\title{
REGENERACIÓN DEL PARLAMENTO, TRANSPARENCIA Y PARTICIPACIÓN CIUDADANA
}

\author{
PIEDAD GARCÍA-ESCUDERO MÁRQUEZ \\ Catedrática de Derecho Constitucional \\ Universidad Complutense de Madrid
}

SUMARIO

I. Regeneración del Parlamento frente a déficit de representación.

II. La transparencia parlamentaria.

III. Parlamento y participación ciudadana.

IV. Otras medidas dirigidas a la recuperación de la confianza en el Parlamento.

V. Conclusión.

\section{REGENERACIÓN DEL PARLAMENTO FRENTE A DÉFICIT DE REPRESENTACIÓN}

\section{Estado de la cuestión}

Los resultados de las elecciones europeas de 25 de mayo de 2014 supusieron un aldabonazo de atención: en general en Europa, en particular en cierto número de países europeos y, entre ellos, en España. Con una fuerte abstención, aunque no especialmente llamativa (el $54.16 \%$ frente al $54 \%$ en las elecciones europeas de 2009), los dos grandes partidos, Popular y Socialista, que hasta entonces podían presumir una alternancia en el poder más o menos cómoda, perdieron juntos, en relación con las elecciones anteriores, cinco millones de votos: del 80,71\% de los votos emitidos pasaron al $49.06 \%$, de 44 escaños entre ambos a 30 de un total de 54. Estos resultados no son anecdóticos, sino el signo de una situación mucho más profunda y general de deterioro de la confianza en las instituciones y los actores políticos, que viene aflorando al menos desde que se agudizó la crisis 
económica mundial que comienza en 2008, y una de cuyas manifestaciones más evidente es el auge de los nuevos partidos antisistema.

La preocupación por los efectos de esta problemática en nuestro sistema político y nuestras instituciones es la que lleva a reclamar con mayor insistencia en los últimos tiempos lo que se ha venido en llamar regeneración democrática, que exige un diagnóstico de la situación y un intento de buscar soluciones. Con ello coincide un movimiento hacia una mayor transparencia de las instituciones - entre otras razones, como medida de lucha contra la corrupción- que las acerque más a la ciudadanía.

En lo que a la institución parlamentaria se refiere, las inadaptaciones o retos venían apuntando desde hacía más tiempo ${ }^{1}$. Hace más de diez años que pretendí sintetizarlos clasificándolos en retos internos, derivados de cada una de sus funciones constitucionales, y externos a la institución, procedentes de una realidad exterior en continua transformación: la globalización, la opinión pública (ahora expresada en una forma no concebible cuando escribía, gracias a internet y las redes sociales, que la han hecho irrumpir en el panorama político con una fuerza inusitada), los medios de comunicación social y las nuevas tecnologías ${ }^{2}$.

Hablar de la crisis del Parlamento no es un tema nuevo, data de 1967 una obra clásica como la de Chandernagor, Un Parlement pour quoi faire ${ }^{3}$. Se han recordado, con ocasión de la revuelta de los indignados en 2011 y también en los días de shock postelectoral de 2014, otras épocas de desplazamiento del papel central del Parlamento a la calle ${ }^{4}$, hoy sustituida en parte por las redes sociales. En mi

1 Puede verse el estudio de TorCal, M., «La confianza en el Parlamento español: tendencias, causas y consecuencias», en Ciudadanía y política, X Jornadas de la Asociación Española de Letrados de Parlamentos, Tecnos, Madrid, 2004, p. 169 y ss.

2 García-Escudero Márquez, P.: «Parlamento y futuro: los retos de la institución parlamentaria», Cuadernos de Derecho Público n. ${ }^{\circ}$ 18, enero-abril 2003, pp. 192-205.

3 Chandernagor, A.: Un parlement pour quoi faire, Gallimard, Paris, 1967. Sobre el tema, entre nosotros podemos citar a Ramirez, M.: «Problemática actual del Parlamento», Revista de Estudios Políticos, n. ${ }^{\circ} 87$, 1995, pp. 53-79; García Morillo, J.: «El Parlamento en la era global», Cuadernos de Derecho Público, n. ${ }^{\circ} 1$, 1997, pp. 77-100; Aguiló Lucià, L.: «El Parlamento en el umbral del siglo Xxi», Corts. Anuario de Derecho parlamentario, n. ${ }^{\circ} 4$ extraordinario, 1997, pp. 15-38. Más recientemente, Tudela ArAnda, J.: El Parlamento necesario. Parlamento y democracia en el siglo XXI, Congreso de los Diputados, Madrid, 2008; Greciet García, E.: «El Parlamento como problema y como solución», Asamblea, n. ${ }^{\circ} 26,2012$, pp. 235-298; NAVArro MÉNDEZ, J.I.: «Algunas propuestas para la mejora del rendimiento institucional de las Asambleas legislativas autonómicas españolas», Asamblea, n. ${ }^{\circ}$ 29, 2013, pp. 65-96. Sobre el Parlamento británico, es particularmente lúcida la visión de Garton Ash, T., «Es urgente renovar el Parlamento británico», El País, 29 de marzo de 2015 .

4 Son plenamente aplicables a nuestros días los ejemplos del desplazamiento del Parlamento desde su importante papel de antaño que cita De Esteban, J. en «La situación del parlamento en las sociedades industriales», Revista de Estudios Políticos n. ${ }^{\circ}$ 159-169, 1968, p. 84. Duverger, M. ( Apogée et déclin du système parlementaire», Les cabiers du Centre d'Études Socialistes, 1963, p. 1, citado por De Esteban, ibidem) recordaba que se viene hablando de crisis del parlamentarismo — aunque no sea lo mismo- desde principios de siglo. Como afirma GARTON Ash, T., «Es urgente renovar el Parlamento británico», cit., nunca hubo una edad de oro; nunca la hay: nos cuentan que cuando el viejo edificio del Parlamento se incendió en 1834, la muchedumbre aplaudió al ver hundirse el tejado. 
artículo anterior calificaba de primer reto con el que se enfrenta el Parlamento el saber mantener su carácter representativo ${ }^{5}$, reto a la vez interno y externo. Esta afirmación se ha revelado tan cierta en los últimos años, que el grito de guerra adoptado como lema por los movimientos cuestionadores del sistema político ha sido «no nos representan» ${ }^{6}$, coreado con virulencia y acompañado de manifestaciones dirigidas al Congreso de los Diputados («rodea al Congreso»); reflejado después en otros datos reveladores, como el aumento de la abstención y —significativamente- de los votos en blanco y nulos en las elecciones generales de 2011, o la disminución de los votos obtenidos por los dos partidos mayores ${ }^{7}$, con la irrupción de nuevos o el crecimiento de otras formaciones políticas, circunstancias que se magnificaron por primera vez en las ya citadas elecciones europeas de $2014^{8}$, donde llegaron a diez las formaciones que obtuvieron escaños, frente a seis en 2009.

La primera cita electoral de 2015 (las siguientes nos van revelando cuál es el desarrollo de la tendencia) ha constituido un segundo aviso: en las elecciones andaluzas celebradas el 22 de marzo, aunque el PSOE mantiene el mismo número de escaños que en las elecciones anteriores (2012), entre los dos grandes partidos han perdido casi un millón y medio de votos desde las elecciones de 2008 (más de un millón desde 2012, pese a aumentar la participación electoral) ${ }^{9}$ y dos partidos nuevos en la plaza, Podemos y Ciudadanos, irrumpen como tercera y cuarta fuerzas parlamentarias ${ }^{10}$.

Decía acertadamente J. Tusell en 1993: la aparición de nuevas fuerzas políticas nos descubre un aspecto esencial de esta apremiante necesidad de repensamiento de la democracia que surge en todas las latitudes. El fenómeno más deci-

5 El profesor Garrorena Morales, A. pronunció sendas conferencias en el XII Congreso de la Asociación de Constitucionalistas de España (Salamanca, 3 de abril de 2014) y en las VII Jornadas de Derecho Parlamentario celebradas en la UNED el 29 de abril de 2014: «Problemas actuales de la democracia representativa: ¿qué hacer?», accesible esta última en http://www.canal.uned.es/serial/index/id/107, en las que realizó un acertado diagnóstico de la situación y propuso distintas medidas.

6 Que no es nueva, por otra parte: De Esteban, J. (La situación del parlamento en las sociedades industriales», cit., p. 92) nos habla del llamado «Poder joven» en 1968, «que abraza a los jóvenes, estudiantes y obreros que, decepcionados de la sociedad de consumo occidental, rechazan las vías parlamentarias — por no sentirse representados- como medios para obtener sus deseos».

7 La suma de los votos de PSOE y PP en las elecciones generales de 2011 alcanza 17.804.573 votos, frente a 21.567.345 en 2008 o 20.661 .654 en 2004.

8 En las que un partido, Podemos, creado dos meses y medio antes de las elecciones y que recogía las reivindicaciones de los «indignados», se convirtió en la cuarta fuerza política, con 5 escaños y 1.245.948 votos, el $7.97 \%$, por debajo del $9.99 \%$ de La Izquierda Plural y por encima del 6.5\% de UPyD. Las circunstancias que hicieron hecho posible este resultado fueron analizadas certeramente por DE EsTEBAN, J. en «El prodigio de Podemos», El Mundo, 27 de mayo de 2014.

9 Elecciones 2015: PSOE, 1.409.042 votos, 35.43\%, 47 escaños; PP, 1.064 .168 votos, $26.76 \%, 33$ escaños. Elecciones 2012: PSOE, 1.527.923 votos, 39.56\%, 47 escaños; PP, 1.570 .833 votos, 40.67\%, 50 escaños. Elecciones 2008: PSOE, 2.178.296 votos, 48.41\%, 56 escaños; PP, 1.730 .154 votos, $38.45 \%$, 47 escaños. La lectura de estos datos debe tener en cuenta la participación electoral, superior en más de medio millón de votantes en 2008 (72.67\% de participación, frente a 60.78 en 2012 y 63.94 en 2015). Fuente: El País.

10 Con 15 y 9 diputados, respectivamente, y casi un millón de votos entre ambos (14.84\% y 9.28\%). 
sivo es una sorda irritación contra la clase dirigente, contra toda ella, sea cual sea su significación, derechista o izquierdista. Si hay una tendencia a no acudir a las urnas y una consideración bajísima de la política como actividad es porque se piensa que los profesionales de la misma no están a la altura de las necesidades actuales ${ }^{11}$.

El déficit representativo de nuestras Cámaras, que puede abordarse desde distintos planos, no es fácil de remediar mediante una modificación normativa, ni siquiera de la propia Constitución, teniendo en cuenta que la función representativa en sí no es objeto de regulación, más allá de la declaración con que se abre el Título III, art. 66 («Las Cortes Generales representan al pueblo español») y la prohibición de mandato imperativo (art. 67.2), o la proclamación en el art. 69.1 de que el Senado es la Cámara de representación territorial. Se trata de un marco o, haciendo mía la visión de De Esteban y González Trevijano ${ }^{12}$, una función genérica que se concreta en el resto de las funciones específicas enumeradas en el art. 66.2.

Como afirmara Hanna Pitkin ${ }^{13}$, el concepto de representación se configura como una continua tensión entre el ideal y el logro; esa tensión debería hacer presente un desafío continuo aunque no desesperanzado: construir instituciones y entrenar a individuos de tal forma que se comprometan en la consecución del interés público, en la genuina representación del público; y, al mismo tiempo, seguir siendo críticos con tales instituciones y con tales aprendizajes con el fin de que siempre se muestren abiertos a posteriores interpretaciones y reformas.

Esta es la visión que debe adoptarse al hablar de regeneración del Parlamento: situarse en la propia institución para intentar recuperar o construir viejas y nuevas funciones, y en todo caso su lugar en el sistema político. En efecto, como he escrito con anterioridad, hoy no basta con un Parlamento, representante formal de la soberanía del pueblo, que asegure con su mera existencia la reserva de un espacio en el esquema de la división de poderes, impidiendo así que pueda llegar a ser ocupado por las tentaciones expansivas de los otros dos poderes, singularmente del ejecutivo.

Tal podía ser la justificación, más que suficiente, necesaria del Parlamento del siglo XIX (que actuaba como elemento introductor de la democracia) e incluso del xx, después de los ataques a la democracia que desembocaron en la Segunda Guerra Mundial.

En el momento actual, todo esto se da por supuesto. No hacen falta símbolos, hacen falta instituciones que se justifiquen por su actuación, por su eficacia real, por las funciones que desarrollan y el papel que desempeñan en el juego

11 Tusell, J.: «La regeneración de la democracia», Cuenta y Razón, n. ${ }^{\circ}$ 78-79, 1993, p. 29.

12 De Esteban, J. y González Trevijano, P.: Curso de Derecho Constitucional, vol. III, Facultad de Derecho UCM, Madrid, 1994, p. 527 y ss.

13 Pitkin, H. F.: El concepto de representación, Centro de Estudios Constitucionales, Madrid, 1985, p. 267. 
activo del entramado de poderes que establece una Constitución, y no por ocupar un puesto en un esquema estático. Éste es el reto de la institución parlamentaria en el futuro: justificar su existencia más allá de por razones históricas, en un escenario que ha cambiado totalmente. Entonces advertía de los peligros de mantener por inercia la misma estructura y los mismos comportamientos en una realidad cambiante que corría el riesgo de desbordarle. Hoy algunos de estos peligros se han convertido en realidad.

En este panorama, se apuntan como instrumentos para luchar contra el déficit de representación de las instituciones en general - y no sólo del Parlamento-_, la transparencia y la participación ciudadana.

\section{Planos del déficit de representación}

Distingamos algunos planos en el déficit de representación del Parlamento:

\section{a) El plano electoral}

Dejaremos fuera de nuestro examen este aspecto. Recordemos tan sólo que la primera de las exigencias del llamado 15-M, plasmadas en un documento de propuestas $^{14}$, era que las listas sean abiertas y con circunscripción única. A esto se ha unido más tarde el debate sobre las elecciones primarias para la selección de los candidatos, intento siempre fallido cuando se pretende aplicar a la realidad. Tal vez podría ser objeto de revisión la proporcionalidad de la fórmula electoral (también incluida en esa primera reivindicación), siempre con el objetivo último de que los resultados reflejen la voluntad popular lo más exactamente posible y los ciudadanos puedan percibirlo mejor, equilibrado con la exigencia básica de gobernabilidad y estabilidad del sistema que ha permitido hasta ahora el funcionamiento del régimen constitucional y electoral.

\section{b) Déficit de democracia participativa}

La reivindicación de las virtudes de la llamada democracia participativa se ha convertido en uno de los leitmotivs de la crítica al sistema democrático ${ }^{15}$. Ello no nos

14 Aprobado en asamblea el 20 de mayo de 2011. Puede verse en http://www.rtve.es/contenidos/documentos/propuestas_movimiento_15M.pdf. «1. Cambio de la Ley Electoral para que las listas sean abiertas y con circunscripción única. La obtención de escaños debe ser proporcional al número de votos».

15 Por continuar con la cita del documento de propuestas del $15 \mathrm{M}$, la n. ${ }^{\circ} 9$ reza: «Democracia participativa y directa en la que la ciudadanía tome parte activa. Acceso popular a los medios de comunicación, que deberán ser éticos y veraces». 
hace abdicar de considerar que nuestra democracia debe seguir siendo básicamente una democracia representativa ${ }^{16}$ y que el Parlamento es hoy por hoy - y esperemos que por mucho tiempo- «un organismo irreemplazable» ${ }^{17}$, pero que caben en aquélla instrumentos complementarios de democracia directa (como prevé por otra parte el art. 23 de la Constitución) que en su día fueron objeto de una visión rigurosa y desconfiada por parte de los constituyentes, tal vez explicable en el contexto histórico, pero que hoy dejaría de tener sentido: número desmesurado de firmas exigidas y limitación de materias innecesaria puesto que están sujetas las proposiciones de ley de iniciativa popular a toma en consideración por el Congreso de los Diputados, exclusión de la iniciativa de reforma constitucional. Es posible que sea en este apartado donde - más como símbolo de una postura renovadora que como decisiva en sus resultados - una reforma constitucional pudiera aportar algunos frutos: iniciativa popular, incluso en materia constitucional, y referéndum pueden ser revisados desde una nueva perspectiva y en este sentido existe alguna propuesta de reforma, tal vez no compartida en todos sus puntos ${ }^{18}$.

El propio Parlamento ha iniciado medidas para permitir la participación de los ciudadanos en el ejercicio de sus funciones, en la línea del llamado Parlamento abierto, a que nos referiremos más adelante, precisamente para tratar de combatir el déficit denunciado a continuación: el divorcio entre Parlamento y sociedad.

\section{c) El divorcio entre Parlamento y sociedad}

El distanciamiento entre la actividad del Parlamento y la realidad social, que en 2003 califiqué de divorcio entre Parlamento y sociedad, se encuentra en la raíz

16 En la rotunda expresión de SARtori, G., «En defensa de la representación», en La Constitución de 1978, veinte años después, Congreso de los Diputados, 2011, p. 109: «La representación es necesaria (no podemos prescindir de ella) y [...] las críticas de los 'directistas' son en gran parte fruto de una combinación de ignorancia y primitivismo democrático». Como afirma DíEz Nicolás, J. («La globalización y las crisis», $A B C, 11$ de abril de 2014), la solución no está en reconocer representatividad a las manifestaciones callejeras, sino en exigir cambios en las instituciones para garantizar mayores niveles de democracia y representatividad, mediante cambios en la legislación electoral y en la organización de la vida política: «deslegitimar las urnas y legitimar las manifestaciones callejeras conducirá necesariamente a legitimar las revoluciones sociales, y eso, no nos engañemos, conducirá a justificar la imposición de regímenes políticos autoritarios, de izquierda o derecha».

17 Hauriou, A.: Derecho Constitucional e Instituciones políticas, Ariel, Barcelona, 1971, p. 687. Como concluye De Esteban, J. su art. pionero, la necesidad de un Parlamento se siente precisamente con mayor agudeza en los países en que éste no existe ( «La situación del parlamento en las sociedades industriales», cit., p. 101). En palabras de Tudela Aranda, J., «Participación en el procedimiento de elaboración de la ley», en Transparencia, participación ciudadana y Administración Púbica en el siglo XXI, Monografías de la Revista aragonesa de Administración Pública, XIV, Zaragoza, 2013, p. 96: complementos, mejoras, sí; sustitución, hasta hoy no. El punto de partida, no obstante, es un modelo en el que los cauces para la participación son elevados.

18 Proposición de reforma de los arts. 87.3, 92 y 166 de la Constitución, presentada por la la Junta General del Principado de Asturias (BOCG Congreso n. ${ }^{\circ}$ 194-1, 24 octubre 2014). Procedente de una Propuesta del Grupo Parlamentario de Izquierda Unida (BOJGPA n. ${ }^{\circ} 16.1,12$ diciembre 2012). 
de la percepción del déficit de representación. Está claro, si se examinan las encuestas de opinión, que la institución parlamentaria, si alguna vez lo fue, en este momento no es capaz de mantener viva su conexión con la ciudadanía, y que se ha generado lo que se ha dado en llamar el desafecto o la desafección ${ }^{19}$, imperante no sólo respecto de los políticos, sino también de las instituciones. Si el Parlamento se aísla de la sociedad a la que representa y no existe esa conexión eficaz con la realidad social y plural, decía entonces (y perdóneseme la continua autocita, que no pretende adjudicarme un poder de profecía, sino situarme en un punto de partida para avanzar en la reflexión), pueden buscarse otros cauces alternativos de representación, que es lo que los nuevos movimientos han pretendido demostrar. Decía también que el Parlamento es acusado de ser ácrono, de vivir fuera del tiempo $^{20}$ (fuera del tiempo legislativo, fuera del tiempo de control, o sea, del tiempo político), lo que origina que deje de ser el eje o el escenario principal del sistema político y se produzca un vaciamiento de la función de poder de la institución parlamentaria ${ }^{21}$. La capacidad del Parlamento para hacer que los ciudadanos se sientan representados reside en parte en su poder de dar respuesta rápida a sus problemas, sus vivencias y sus inquietudes.

Sigo pensando, y en esta vía han pretendido avanzar las iniciativas internacionales en favor de la transparencia ${ }^{22}$, que el Parlamento debe acercarse a los ciudadanos, hacerse próximo, que éstos le sientan suyo y conozcan su actuación. Debe destruir mitos como que los parlamentarios no trabajan o que el Parlamento no sirve para nada, y debe hacer conocer su actividad, sus funciones, sus procedimientos y el porqué de los mismos y de su existencia. En nuestro país, tal vez al haber dado por sentado el sentimiento democrático y parlamentario de los ciudadanos, se ha perdido tiempo en hacerles llegar las cualidades representativas de la institución.

El uso de las nuevas tecnologías — que se preveían útiles para estrechar y facilitar la relación entre institución parlamentaria y representados-como me-

19 Puede verse Presno Linera, M.A.: «La voz del desafecto: razones y propuestas» en http://presnolinera.files.wordpress.com/2014/05/la-voz-del-desafecto.pdf.

20 Garcia Morillo, J.: «El Parlamento en la era global», cit., p. 79 y ss.

21 Véase el interesante análisis de Vallespín, F., «Teatrocracia», El País, 20 de febrero de 2015: «El Parlamento ha perdido su distancia, y con ello casi toda su auctoritas. Los políticos lo han abandonado en busca de la «cercanía» que les brindan las redes sociales y las ondas televisivas y se ofrecen gustosos como mercancía de consumo instantáneo para una audiencia expectante por ver quién despelleja a quién. Las confidencias, los rumores, los chismes internos de los partidos cotizan más que los discursos y los programas. Y los datos, la cultura de los datos que nos ofrecen las encuestas. No en vano estas permiten que el público pase a formar parte de la representación, se suba al escenario y sea un actor más en la función de la teatrocracia». En el mismo sentido, GARTON Ash, T., «Es urgente renovar el Parlamento británico», cit.: se pierde la sustancia de la democracia deliberativa o queda en manos de los periodistas. Un buen interrogatorio de un veterano entrevistador televisivo consigue mucho más que cien sesiones en el Parlamento.

22 De la que es muestra el Índice de transparencia de los Parlamentos auspiciado por Transparencia Internacional. Puede verse la primera evaluación de la transparencia de los 19 Parlamentos españoles, publicada en 2014, en http://www.transparencia.org.es/IPAR/INDICE_IPAR_2013.htm, en la que 16 de ellos han obtenido una calificación superior al 50 por 100, como veremos más adelante. 
canismo de acercamiento ha puesto también de relieve las carencias y dificultades de las mismas (por ejemplo, el fracaso de las redes sociales institucionales por falta de feedback o la escasa respuesta en iniciativas abiertas a la participación pública $^{23}$ ).

\section{d) La relación entre representantes y representados}

Esta relación es susceptible de examen en varias vertientes:

1. Falta de democracia interna de los partidos políticos, en mi opinión déficit capital de nuestro sistema político - aunque no entre directamente en el objeto de análisis de este trabajo - hasta cierto punto relacionado con el déficit democrático de las Cámaras, y en todo caso denunciable. Los partidos políticos, y no sólo los dos mayoritarios, se han convertido en instituciones tan burocratizadas y gobernadas desde la cúspide (confirmando una vez más la ley de hierro de $\mathrm{Michels}^{24}$ ) como los departamentos ministeriales, con todos sus vicios y defectos de funcionamiento: organizaciones costosas, con exceso de personal, falta de transparencia y de agilidad en su funcionamiento interno, en definitiva con muchos condicionantes para poder anteponer en su actuación el interés público a todo lo demás ${ }^{25}$.

2. Descrédito de la institución parlamentaria. La falta de democracia interna de los partidos políticos afecta no sólo a las relaciones con sus militantes, sino a la percepción que los ciudadanos tienen de su papel, y en consecuencia también del que desempeñan las instituciones de democracia representativa en las que se integran y los representantes que sirven de intermediarios entre el pueblo y esas instituciones. Al fin y al cabo, la visión de una Cámara parlamentaria es la de una institución compuesta por la suma de las formaciones políticas que la componen, esto es, de los parti-

23 Sobre la problemática que rodea al Parlamento 2.0 o al llamado Parlamento abierto, pueden verse los distintos trabajos que forman la obra coordinada por RuBIo NúÑEZ, R.: Parlamentos abiertos. Tecnología y redes para la democracia, Congreso de los Diputados, Madrid, 2014, en particular los de CAMPos Domínguez, E., Coello de Portugal, J.M y Aguilar Nacher, I. Véase también Tudela Aranda, J.: El Parlamento necesario. Parlamento y democracia en el siglo XXI, cit., p. 46 y ss., y NAVArro MÉNDEZ, J.I.: «Algunas propuestas para la mejora del rendimiento institucional de las Asambleas legislativas autonómicas españolas», cit., p. 83 y ss.

24 Véase Michels, R.: Los partidos políticos 2. Un estudio sociológico de las tendencias oligárquicas de la democracia moderna, Amorrortu ed., Buenos Aires, 1979, en particular p. 164 y ss.

25 En descripción de Vírgala Foruria, E.: «Crisis de la representación y democracia directa en España», Asamblea, n. ${ }^{\circ} 29,2013$, p. 11, en la práctica política se ha producido la transformación de los grandes partidos nacionales en maquinarias dirigidas a obtener y mantenerse en el poder, pero con una militancia reducida en número y con unos procesos internos de escasa democracia, a la vez que se convierten en los canales prácticamente exclusivos de participación institucional de los ciudadanos. 
dos, y su comportamiento y actitud influyen en que sea creíble la función representativa de aquélla.

Aquí deberíamos incluir una mención a las prerrogativas parlamentarias, no tanto las institucionales o colectivas derivadas de la autonomía, que siguen siendo fundamentales para la salvaguardia de la separación de poderes (inmunidad de sede, autogobierno, autonomía reglamentaria y de personal) sino las individuales de los parlamentarios: inmunidad, inviolabilidad y fuero especial.

A mi juicio, no son tanto estas prerrogativas, hoy reducidas a mínimos — salvo el aforamiento — por la doctrina del Tribunal Constitucional, sino su presentación por los medios de comunicación la que puede dañar a la institución parlamentaria. Pueden restringirse las dos primeras de acuerdo con la jurisprudencia constitucional y los ejemplos constitucionales comparados, pero un núcleo esencial de inviolabilidad y de inmunidad limitadas a las funciones parlamentarias creo que debería salvarse de la poda.

3. Carencia absoluta de protagonismo del parlamentario individual, en teoría el auténtico representante del electorado y en último término de la Nación, depositario de la relación representativa. El representante individual cuenta a su favor apenas con la prohibición de mandato imperativo que le sirve de escudo, al menos formal, frente a la fuerza invasora de sus competencias por parte de los partidos políticos y de su trasunto los grupos parlamentarios ${ }^{26}$, así como con la reserva en los Reglamentos parlamentarios de algunas iniciativas (pocas: preguntas y enmiendas), mermadas

26 Un análisis de la situación en García-Escudero Márquez, P.: «El parlamentario individual en un Parlamento de grupos: la participación en la función legislativa», Teoría y Realidad Constitucional n. ${ }^{\circ} 28$, 2011, en especial p. 210 y ss. Considero importante la presencia en la Constitución del art. 67.2, que pervive también en las Constituciones de nuestro entorno (italiana, art. 67: «Cada miembro del Parlamento representa a la Nación y ejerce sus funciones sin estar ligado a mandato alguno»; francesa, art. 27: «Todo mandato imperativo es nulo»; la portuguesa establece que los diputados representan a todo el país y no a las circunscripciones por las que son elegidos — art. 152-y declara que los diputados ejercen libremente su mandato, art. 155, si bien el art. 163.1.c dispone que pierden su mandato cuando se inscriban en un partido distinto de aquél por el que se han presentado a las elecciones), aunque en la realidad no exista libertad respecto del partido y sus decisiones. Como dice PENDÁs, B.: «Formas de gobierno. Notas para un debate sobre el parlamentarismo adaptado», Asamblea, n. ${ }^{\circ}$ 6, 2002, p. 9, los grupos parlamentarios y la Junta de Portavoces van ganando día a día posiciones concretas de poder sobre el parlamentario singular, sin necesidad de modificar la letra de las Constituciones y Reglamentos: el mandato imperativo sigue jurídicamente prohibido, pero el mandato de partido le ha ganado para siempre la batalla política. No obstante, comparto con GArcía PeLAYo, M. que la presencia en los textos constitucionales de la prohibición de mandato imperativo cumple, cuando menos, la función de garantizar jurídicamente la libertad de juicio y de voto del representante (El Estado de partidos, Alianza, Madrid, 1986, p. 100). En el mismo sentido, Rubio Llorente, F. («La representación política», en

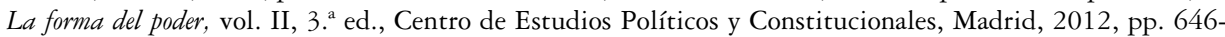
647): una cosa es la vinculación fáctica y otra bien distinta su transformación en obligación jurídica, y es esta transformación lo que el principio de interdicción del mandato imperativo pretende impedir. Hoy ese principio es más imprescindible que nunca, por «la necesidad de mantener tan abierta como sea posible la relación entre los partidos y la sociedad». La relación entre electores y elegidos, que la interdicción del mandato im- 
en su ejercicio por la exigencia, en la norma o en la práctica, de la firma del portavoz del grupo. La partitocracia en el seno del Parlamento se transforma en grupocracia y el diputado desaparece como representante, absorbido - fagocitado- por su grupo $^{27}$.

Como señala Rubio Llorente, el Parlamento no es hoy, como en su imagen ideal, un cuerpo integrado por representantes individuales que actúan con plena libertad y no están sujetos a mandato imperativo alguno, sino por grupos, cuya voluntad se impone a la de sus miembros ${ }^{28}$.

El peligro de esta grupocracia, como ya hemos denunciado en más de una ocasión, es que los ciudadanos lleguen a percibir como superflua la existencia de los parlamentarios, lo que arrastraría la innecesariedad del propio Parlamento. Bastaría con asignar un cupo de voto a cada candidatura en función de los resultados de las elecciones y con una reunión de lo que sería el trasunto de la actual Junta de Portavoces, que votara para resolver cuantas cuestiones ahora se someten al Parlamento.

Debe reforzarse, por tanto, la idea de que el Parlamento existe porque existen los parlamentarios, los representantes del pueblo. Acentuar su contacto y conocimiento por su circunscripción, difundir las funciones que cumplen. Y darles juego, aprovechar sus potencialidades y sus deseos de trabajar, de todos ellos, no sólo los de los grupos pequeños saturados de intervenciones e iniciativas, sino también de todos los de los grupos grandes. Hemos de seguir clamando, pues, contra algo que tal vez sea irremediable pero que debe ser objeto de reflexión para que la Cámara no se convierta en algo inútil, perfectamente sustituible por unos portavoces con voto ponderado en función de los resultados electorales ${ }^{29}$, tenien-

perativo permite en alguna medida preservar es la que ha inspirado la doctrina del Tribunal Constitucional desde las tempranas sentencias de 1983.

27 El grupo filtra sus iniciativas, decide cuándo y de qué puede hablar, le asigna sus Comisiones, le dice lo que tiene que votar (frente a la prohibición de mandato imperativo), le sanciona por falta de asistencia o por votar libremente, incluso por equivocarse; en ocasiones hasta vota por él: en los supuestos de voto ponderado, pese al carácter personal e indelegable del voto, proclamado por la Constitución. Véase la reserva a los grupos parlamentarios de la mayor parte de las iniciativas parlamentarias por los Reglamentos en GARCíaEsCudero MÁrquez, P.: «El parlamentario individual en un Parlamento de grupos: la participación en la función legislativa», cit., p. 216 y ss.

28 Rubio Llorente, F.: «Defectos de forma», Revista Española de Derecho Constitucional, n. ${ }^{\circ} 100$, 2014, p. 138. Y añade: también en el Parlamento decimonónico había una cierta subordinación del representante individual al grupo, como puede verificarse en los Diarios de Sesiones y evidencia el esfuerzo de Bentham para justificarla. La realidad actual es sin embargo sustancialmente distinta no sólo por la intensidad de la sujeción, sino sobre todo porque la voluntad que se impone no es la del grupo parlamentario, en cuya formación participan sus miembros, sino la del partido, es decir, la de sus dirigentes.

29 La STC 57/2011, que avala el requisito reglamentario de previo conocimiento para las peticiones de informe por los diputados, no ayuda en este sentido, pues no parece poner gran empeño en reivindicar el papel del parlamentario individual frente al grupo parlamentario en el ejercicio de las funciones constitucionales. Véase su análisis en García-Escudero Márquez, P.: «El parlamentario individual en un Parlamento de grupos: la participación en la función legislativa», cit., p. 218 y ss. 
do en cuenta además que la disciplina del grupo — con aplicación de sanciones económicas por inasistencia o por quebrantar la disciplina de voto- puede coartar realmente la posibilidad de libre ejercicio de su función por los parlamentarios individuales ${ }^{30}$. La propia institución parlamentaria tiene una labor que cumplir facilitando a los parlamentarios los medios necesarios para desarrollar sus funciones, dotándoles de mayor asistencia personal y material.

La regeneración del Parlamento debe contar, pues, con el fortalecimiento del papel del parlamentario individual sin privar de su necesario protagonismo a los grupos parlamentarios, lo que en otro lugar he llamado conseguir la cuadratura del círculo ${ }^{31}$.

\section{La necesidad de renovación de las funciones parlamentarias}

También en el ejercicio de sus funciones necesitan las Cámaras una renovación en aras de la regeneración de la institución parlamentaria y su mejor adaptación a los tiempos actuales.

\section{a) La función legislativa: legislar o ratificar}

La reciente y prolongada crisis económica nos ha aportado una muestra clara de la supuesta incapacidad del Parlamento para regir con mano firme y rápida los destinos económicos del país en una era de globalización: el gobierno por decreto-ley (29 decretos-leyes en 2012, 17 en 2013 y 2014, 11 en 2015 hasta la disolución de las cámaras, frente a 17 leyes ordinarias y 8 orgánicas en 2012, 27 y 9 en 2013, 36 y 8 en 2014, 47 y 16 en 2015), que por supuesto ha de convalidar el Congreso de los Diputados por imperativo constitucional ${ }^{32}$ (incluso tramita algu-

30 Como muestra de que la valoración pública del Parlamento de Westminster atraviesa horas bajas, Garton Ash, T., «Es urgente renovar el Parlamento británico», cit., recuerda que cuando se dijo que tal vez los parlamentarios tengan que mudar provisionalmente sus despachos a algún lugar fuera de Londres durante las obras, los programas de radio se llenaron de llamadas en las que se sugería a los señores diputados que se vayan y, a ser posible, no vuelvan. Uno de los motivos para este desprecio que cita es que muchos diputados dependen directamente de los líderes del partido, ocupando cargos en el Gobierno o desempeñando funciones paralelas en la oposición.

31 García-Escudero Márquez, P.: El procedimiento legislativo ordinario en las Cortes Generales, Centro de Estudios Políticos y Constitucionales, Madrid, 2006, p. 675. Greciet García, E. («El Parlamento como problema y como solución», cit., p. 270) propone como medidas orientadas a dicho objetivo: un cupo de asuntos de los diputados en el orden del día; el incremento de la cantidad y calidad de las iniciativas abiertas a la autoría de los diputados, la asignación a éstos de turnos específicos en los debates; la potenciación de la figura del ponente individual en todos los procedimientos, tal como prevé el Reglamento del Parlamento Europeo. Serían estas materias típicas de regulación reglamentaria, pero sobre todo necesitadas de la voluntad política de hacerlas realidad.

32 Véase en Rubio Llorente, F. («Defectos de forma», cit., p. 146) el análisis de la diferencia entre el modelo constitucional español y el italiano, al que se supone copiaba: la derogación a los treinta días - bas- 
nos como proyectos de ley, no muchos: 10 en 2012, 2 en 2013, 3 en 2014 y 2015), no sería sino un ejemplo más de la denunciada incapacidad del Parlamento para legislar rápida, masiva y tecnificadamente.

Recordemos la llamada hipertrofia de la legislación en el tercer tercio del siglo Xx que llevó a Sartori a diagnosticar hace medio siglo ${ }^{33}$ el surménage crónico que sufre el Parlamento, incapaz de hacer frente con la celeridad exigible a la demanda de producción legislativa con sus medios materiales y personales, con sus inveteradas pautas de comportamiento y con sus anticuados métodos de trabajo.

No obstante, frente a estas afirmaciones puede argumentarse que el Parlamento deja de lado —o acomoda - sus rígidos procedimientos cuando el consenso político y la demanda social se lo exigen. El procedimiento legislativo es adecuado para que mayoría y minoría puedan exponer sus posiciones y, al menos teóricamente, traten de llegar al acuerdo más amplio y acertado posible. Tal y no otra es la función del Parlamento, donde se viene a parlamentar, a deliberar, a discutir. Y tal es el sentido de su carácter de órgano representativo de las distintas posiciones políticas existentes en el electorado, al que se atribuye la función de legislar ${ }^{34}$.

Deben no obstante formularse propuestas que, probablemente en el marco de los Reglamentos parlamentarios (salvo en cuanto a iniciativa popular y referéndum incida en materia de reforma constitucional), intenten acomodar el procedimiento legislativo, dotándolo de la máxima transparencia, y revitalizando la labor de la oposición y del parlamentario individual.

Como exponía en una obra anterior dedicada al procedimiento legislativo ${ }^{35}$, en lugar de lamentar la pérdida de poder del Parlamento o el empobrecimiento de la función legislativa ${ }^{36}$, debe potenciarse su actuación necesaria ${ }^{37}$, intentando que el procedimiento cumpla con sus dos funciones de mejorar técnicamente (en su doble vertiente formal y de adecuación a la realidad) y propiciar el consenso sobre los textos que el Ejecutivo le remite. No sólo fiscalizando esa decisión del

tante improbable, añado yo, ya que apenas se recuerda un precedente de no convalidación — no impide que el decreto-ley haya surtido efectos.

33 SARTori, G.: «L'avenir des Parlaments», en Bulletin SEDEIS, n. ${ }^{\circ}$ 74, 1964, p. 31.

$34 \mathrm{Y}$, cualquiera que sea el sujeto que dicte normas con rango de ley, el debate parlamentario es insustituible para dar voz a las distintas formaciones políticas representadas, evitando la auténtica dictadura incontrovertida del ejecutivo. Si la convalidación es mera ratificación, en todo caso es también control por parte de la oposición, o dicho de otra manera, permite a las minorías parlamentarias expresar públicamente su opinión, de cara al electorado como último destinatario. p. 671 .

35 García-Escudero Márquez, P.: El procedimiento legislativo ordinario en las Cortes Generales, cit.,

36 No se trata, dice Pendás García, B. («Formas de gobierno. Notas para un debate sobre el parlamentarismo 'adaptado'», cit., p. 12), de cambiar el rótulo, sino de asumir las consecuencias: he aquí el Parlamento y el régimen parlamentario que nos ha tocado vivir; lo demás, como en el poema de T.S. Elliot, es simplemente «el eco en la memoria de los pasos fallidos».

37 Véanse algunas propuestas para el «parlamentarismo estructurado», en García Morillo, J.: «Mitos y realidades del parlamentarismo», Revista Española del Centro de Estudios Constitucionales, n. ${ }^{\circ}$ 9, 1991, p. 138 y ss. 
Gobierno en relación con su programa, sino intentando, en su caso, modificar su formulación para mejorarla, de forma que no sea cierta la expresión de Quaritsch «ley parlamentaria sin Parlamento» ${ }^{38}$, sino que la intervención del Parlamento tenga sentido y sea fecunda.

De otra parte, convendría revisar las normas reglamentarias relativas al procedimiento legislativo para introducir (como ya han hecho algunos Reglamentos autonómicos, como Andalucía y Cataluña) las audiencias de expertos e interesados en la tramitación de los proyectos de ley. Tal vez ello pueda contribuir al acercamiento a la sociedad que constituye uno de los retos actuales de la institución parlamentaria ${ }^{39}$, objetivo a procurar en el procedimiento legislativo, pues traerían a la sociedad al Parlamento y permitirían a éste pulsar los estados de la opinión.

Otras formas de apertura por vía electrónica instauradas también en Parlamentos autonómicos (aportaciones de la ciudadanía a los procesos legislativos que veremos en el apartado III) no han tenido el éxito de participación pretendido ${ }^{40}$, pero sirven como muestra de un cambio de actitud que puede mover a la reflexión.

El perfeccionamiento en la información de las comisiones legislativas y sus miembros también debe ser un logro a perseguir. Han revelado su utilidad en la preparación de textos legislativos importantes (la profesionalización de las fuerzas armadas, o la reforma de la previsión social, por ejemplo) los estudios previos, cuyas conclusiones consensuadas permiten agilizar considerablemente la tramitación posterior. En este sentido, parece que sería conveniente incorporar en ocasiones las subcomisiones, ponencias o comisiones de estudio a la función legislativa ${ }^{41}$.

Un reforzamiento del papel de la ponencia potenciando sus atribuciones, reconociendo las que ejerce en la actualidad en cuanto a la aceptación de enmiendas, la negociación política y la mejora del texto de los proyectos de ley, podría mejorar la tramitación parlamentaria. Asimismo, sería útil permitir a la ponencia mantener contactos con el Gobierno y con los sectores afectados o expertos, éstos en el ámbito informal y no público de la ponencia, a diferencia de las audiencias de la Comisión. La ponencia podría continuar desempeñando sus funciones du-

38 Véase Parejo Alfonso, L.: Crisis y renovación en el Derecho Público, Centro de Estudios Constitucionales, Madrid, 1991, p. 56; sobre el fundamento actual de la reserva de ley, p. 58.

39 Véase García-Escudero Márquez, P.: «Parlamento y futuro: los retos de la institución parlamentaria», cit., p. 191 y ss.

40 Un análisis de algunas experiencias en Gonzalo Rozas, M.A. y Cavero Cano, G., «Iniciativas de los Parlamentos para promover la participación ciudadana: buenas prácticas», Revista de las Cortes Generales, n. ${ }^{\circ} 88,2013$, p. 201 y ss.

41 Coincidimos con Greciet, E. («Un Parlamento diferente», El Diario.es, 18 de abril de 2013) en que ha de escenificarse la idea del Parlamento como lugar de resolución de conflictos sociales y políticos. «Una potente política de comunicación institucional debe ser el altavoz que lo propague y que, asimismo, haga bueno el trabajo de las Comisiones, verdadero centro gravitatorio de la actividad parlamentaria cotidiana donde se debaten asuntos de extraordinaria importancia y amplia especialización que no siempre — por no decir casi nunca- encuentran la resonancia que merecen». 
rante el resto del procedimiento, formulando propuestas de transacción para aproximar posiciones y velando por la corrección técnica de los textos posteriores.

Uno de los objetivos de las eventuales reformas reglamentarias ha de ser la agilización de procedimientos, entre ellos el legislativo ${ }^{42}$. La flexibilidad del mismo debe permitir afrontar las necesidades de celeridad en la tramitación de determinados proyectos o proposiciones, a la vez que conocer de alguna manera - aun sabiendo los imponderables y ponderables políticos que intervienen en este punto- la programación legislativa de la Cámara para el periodo de sesiones, que permita conocer de antemano un cierto calendario de tramitación de cada proyecto o proposición de ley ${ }^{43}$.

La agilización debe afectar asimismo a los debates, permitiendo la confrontación de posiciones y la adaptación a las circunstancias, evitando que las sesiones se conviertan en una sucesión de monólogos de sordos.

En cuanto a la potenciación de la participación del parlamentario individual sin privar del protagonismo debido a los grupos parlamentarios, hemos reclamado la supresión de la exigencia reglamentaria de la firma del portavoz para las enmiendas de parlamentarios individuales. Pero al mismo tiempo reconocemos que el papel fundamental en el debate sobre posiciones políticas en el Pleno debe reservarse a los grupos parlamentarios. Por tanto, parece que la Comisión debería ser el foro donde se escuchara la voz de los parlamentarios para hacer patente su

42 Respondiendo a los defectos enunciados por CANO BUESO, J. ( Procedimiento legislativo y análisis de adecuación de las normas a la realidad», en Los procesos de implementación de las normas jurídicas, A. FigUEROA Laraudogoitia (coord.), Instituto Vasco de Administración Pública, Oñate, 1995, p. 130) con expresiones tales como decisiones paralizantes, lentitud exasperante, reiteración temática, ritualidad, obstruccionismo, dispersión y fragmentación de la actividad legislativa, cuyo resultado sería una producción normativa con frecuencia incoherente, farragosa, repetitiva y escasamente imaginativa. Para Rubio Llorente, F. («Función legislativa, poder legislativo y garantía del procedimiento legislativo», en El procedimiento legislativo. V Jornadas de Derecho Parlamentario, Congreso de los Diputados, Madrid, 1997, p. 31), el único remedio eficaz para acelerar el procedimiento legislativo es reducir el input, pues en último término la obsesión por la celeridad puede reducir al Parlamento a una simple máquina para ratificar automáticamente los proyectos gubernamentales. Frente a ello, le cabe al Parlamento estimular el recurso a las leyes de bases y las remisiones al Reglamento. La delegación en el Gobierno mediante leyes de bases, decía GArcía MoriLlo, J.: («Mitos y realidades del parlamentarismo», cit., p. 142), no cabe sostener que suponga la dejación del poder político en manos de los técnicos. La utilización de la legislación delegada en Gran Bretaña como forma habitual de la producción legislativa no ha redundado en un vaciamiento del poder del Parlamento, sino más bien al contrario, en un reforzamiento de su función política y de su protagonismo en la dinámica política.

43 Uno de los aspectos sobre los que incidía la reforma del Reglamento de la Camera italiana de 1997 eran la programación y el calendario de los trabajos, intentando conseguir una certeza en los tiempos de decisión adecuada a la complejidad de los asuntos (fijando un plazo máximo y un plazo mínimo para la actividad de las comisiones) y una programación trimestral de los trabajos. ZAMPETTI, U., Secretario General de la Cámara («Il procedimento legislativo», Rassegna Parlamentare, n. ${ }^{\circ} 1,2001$, p. 137), cree que se obtuvo una mejora evidente en este punto, reduciéndose además en el procedimiento ordinario el tiempo medio de examen de los proyectos de ley. Igualmente, la programación de la tramitación de los proyectos de ley fue una de las preocupaciones de la Comisión especial para la modernización de la Cámara de los Comunes, entendiendo que en ella deben involucrarse todas las partes, especialmente el Gobierno. Véanse las conclusiones y recomendaciones del primer informe (publicado el 3 de noviembre de 2003, pp. 9-12), que finalizan insistiendo en que la programación debe enmarcarse en la reforma global del procedimiento legislativo. 
participación en el procedimiento legislativo. El objetivo ha de ser alcanzar la integración de los parlamentarios en la formación de la ley, de manera que ésta se aproxime lo más posible a la opinión mayoritaria de los ciudadanos expresada en las urnas ${ }^{44}$.

No cabe olvidar la técnica legislativa en una regeneración del procedimiento. El propio Ejecutivo (también los autores de proposiciones) debería intentar mejorar la redacción de los proyectos de ley, introduciendo un examen técnico de los mismos antes de elevarlo al Consejo de Ministros y cumpliendo las normas que él mismo se dicta ${ }^{45}$, en particular las Directrices de Técnica normativa aprobadas por acuerdo de Consejo de Ministros de 22 de julio de 2005.

En el procedimiento parlamentario, distintas medidas podrían mejorar la calidad de las leyes: así, regular la calificación de las enmiendas, imponiendo su homogeneidad y congruencia con el texto enmendado, como exige la reciente doctrina revisada del Tribunal Constitucional ${ }^{46}$ para evitar las leyes pluricéfalas que complican nuestro ordenamiento hasta extremos impensables; mejorar el contenido de los documentos que reflejan la tramitación parlamentaria, en particular el informe de ponencia y el mensaje motivado que acompaña a las enmiendas del Senado, al objeto de que contengan realmente la justificación de las modificaciones introducidas y faciliten un mejor conocimiento de la voluntad del legislador; introducir una verificación formal de las enmiendas transaccionales $o$ in voce, que permita (en el curso del debate o con posterioridad a su aprobación, dado lo apresurado de su tramitación) adecuarlas a los caracteres del texto y ubicarlas correctamente en la sistemática del mismo; permitir la adaptación de la redacción de la exposición de motivos, de forma escueta y neutra, a las modificaciones que se introduzcan en el articulado, incluso en la aprobación final (esto podría realizarse mediante una habilitación formularia por el Pleno a los servicios de la Cámara al final de la aprobación de cada proyecto, lo que en ocasiones — proyecto de ley de presupuestos - se hace a otros efectos); e incluso introducir algún procedimiento que obtuviera los mismos resultados que las históricas Comisiones de estilo, sea en

44 Teniendo las demás consideraciones, según Biglino Campos, P. («Veinticinco años de procedimiento legislativo», Revista de Derecho Político, n. ${ }^{\circ}$ 58-59, 2003-2004, p. 455), entre las que estarían procurar la agilidad del procedimiento, evitar el obstruccionismo, salvaguardar la disciplina interna de los partidos o garantizar la libertad de sus miembros, valor instrumental en relación con dicha finalidad.

45 Véase García-Escudero Márquez, P.: La iniciativa legislativa del Gobierno, Centro de Estudios Políticos y Constitucionales, Madrid, 2000, p. 91 y ss. En el «Prólogo» a esta obra (p. XV), F. SÁINZ MoreNO afirma que en ella se muestra que la calidad de la ley viene, en gran medida, determinada por la calidad del proyecto de ley. «El Parlamento puede retocar y reformar un proyecto, pero si este es constitutivamente malo, poco puede hacer. Un edificio mal proyectado, mal calculado, no ajustado a la realidad, puede sufrir un 'reformado', pero siempre padecerá, más o menos disimulados, sus vicios de origen. Por el contrario, si el proyecto es bueno, podrá resistir mejor malas enmiendas».

46 Iniciada con la importante sentencia 119/2011. Véase GARCía-Escudero MÁrQUEZ, P.: «De enmiendas homogéneas, leyes heterogéneas y preceptos intrusos. ¿Es contradictoria la nueva doctrina del Tribunal Constitucional sobre elaboración de las leyes?», Teoría y Realidad Constitucional, n. ${ }^{\circ} 31,2013$, pp. 199-236. 
el curso del procedimiento o tras la aprobación, de mayor dificultad porque soy consciente de que son pocas las correcciones puramente formales, que no tengan incidencia en aspectos sustantivos.

Creo que estas propuestas son todas ellas concretas, limitadas y prácticas, de relativamente fácil introducción en los Reglamentos (otra cosa es que su cumplimiento fuera real) y posiblemente de resultados apreciables a corto plazo en la mejora de la calidad de las leyes y la coherencia del ordenamiento.

De otra parte, cada vez cobra mayor relevancia la evaluación de las leyes aprobadas por el Parlamento para la comprobación de su adecuación al objeto perseguido: puede sugerirse un seguimiento de la efectividad de las leyes aprobadas y de las dificultades de su aplicación, para lo que podrían habilitarse distintas fórmulas: desde una subcomisión en el seno de la Comisión legislativa competente, hasta informes periódicos del Gobierno (por ejemplo, aportando los datos cuantitativos de los efectos de determinadas medidas legislativas ${ }^{47}$, que a su vez puedan dar lugar al ejercicio de su iniciativa legislativa por los grupos parlamentarios o a instar la acción del Gobierno mediante proposiciones no de ley.

El mayor conocimiento repercutirá en una mejor labor legisladora, tanto más en una época en que las reformas de las leyes se suceden a ritmo, si no vertiginoso, cuando menos rápido ${ }^{48}$.

Finalmente, cabe reflexionar sobre la posibilidad de que en la convalidación de los decretos-leyes por el Congreso de los Diputados pueda facilitarse la tramitación como proyecto de ley del decreto-ley convalidado, de manera que si lo solicita un número amplio de diputados o de grupos no quepa la denegación por la mayoría que apoya al Gobierno.

\section{b) La función de control: inadecuación de los instrumentos}

Podemos constatar la inadecuación de los actuales instrumentos de control para la finalidad que pretenden, esto es, verificar si la acción del Gobierno se aco-

47 Algunos mecanismos de evaluación: la Comisión de seguimiento y evaluación del acuerdo del Pacto de Toledo, constituida como Comisión no Permanente en el Congreso de los Diputados desde 1999 (antes existía como subcomisión) para el examen de la evolución del sistema de previsión social, o las cláusulas incorporadas como disposiciones adicionales en distintas leyes, que prevén el envío por el Gobierno a las Cámaras de informes sobre el cumplimiento de aquéllas. También la creación de la Oficina presupuestaria de las Cortes Generales por Ley 37/2010 puede colaborar en esta dirección. Véase GARCía-EsCudERO MÁrQUEZ, P., Técnica legislativa y seguridad jurídica, Civitas-Aranzadi, Cizur Menor, 2010, p. 183 y ss., así como Manual de Técnica Legislativa, Civitas-Aranzadi, Cizur Menor, 2011, p. 59 y ss. y p. 78 y ss.

48 El legislador interviene con demasiada frecuencia (las «leyes fáciles» de ELIA), dice OliveTti, N. («Processo legislativo», en Dizionario di politica, BobBio, N. y MatTeucci, N. dirs., UTET, Turín, 1976, p. 789), sea para corregir los errores de las leyes precedentes no suficientemente ponderadas (en cuyo caso puede hablarse de excesivo «experimentalismo»), sea para disciplinar materias que podrían ser confiadas a fuentes subordinadas. 
moda o no al criterio del Parlamento y exigir, en caso de que el examen resulte negativo, la responsabilidad del Gobierno o imponer su cese.

En un sistema parlamentario como el nuestro, en que la mayoría quiere lo que quiere el Gobierno, es ilusorio pensar que aquélla controle o éste se deje controlar. No obstante, aquí como en la función legislativa, el Parlamento no debe caer en la tentación de olvidar que es algo distinto del Gobierno, aunque comparta la misma filiación política. La oposición denuncia que la mayoría impide (en uso legítimo del Reglamento, cabría añadir) la celebración de comparecencias o dificulta la creación de comisiones de investigación, de forma que el Parlamento no podrá ejercer su función de control.

También aquí las propuestas han de centrarse en una reforma de los Reglamentos parlamentarios, casi más trabajosa y difícil de conseguir que una reforma constitucional ${ }^{49}$ :

- las preguntas orales en Pleno, que permiten una mayor repercusión mediática, son utilizadas también por la mayoría que apoya al Gobierno ${ }^{50}$, sin que su objeto sea controlar sino permitir el lucimiento del Gobierno al brindar información o incidir en los logros conseguidos; tal vez sea excesivo proponer la supresión de las preguntas de la mayoría, pero planteémonos una reflexión al respecto.

- en cuanto a las preguntas para respuesta escrita, su volumen (que crece exponencialmente en cada legislatura, alcanzando 104.313 en la IX y «sólo» 82.311 en la $\mathrm{X}$ que acaba de concluir) ahoga su posible utilidad como instrumento de control e información, porque impide distinguir el grano de la paja;

- las interpelaciones (cuya tramitación ni siquiera se rige ya por los obsoletos Reglamentos de 1982, sino por acuerdos de la Junta de Portavoces adoptados al inicio de la legislatura) se han convertido en preguntas ampliadas, en cuyo debate en el Congreso de los Diputados, por acuerdo de los propios grupos, ya no intervienen los grupos no interpelantes. La ausencia casi total de parlamentarios (como por otra parte también de representantes de los medios de comunicación) en el salón de sesiones al final de una sesión de control, en la que no se producen votaciones, no favorece el interés por este instrumento, que se convierte en una

49 En la práctica el Reglamento del Congreso, dice Rubio Llorente, F., ha resultado tan rígido como la Constitución misma, hasta el punto que ha sido necesario acudir a una fuente peculiar, las «Resoluciones interpretativas» de la Presidencia, para regular materias tales como el procedimiento de reforma de los Estatutos de Autonomía o el de control del Gobierno («Defectos de forma», cit., p. 145).

50 Una corrección al sistema de cupos en función del tamaño del grupo, en el trámite de las preguntas orales en Pleno, se introdujo por la Resolución de la Presidencia del Congreso de los Diputados de 10 de junio de 2008, sobre desarrollo del art. 188 del Reglamento, relativo a preguntas para respuesta oral en Pleno, que al menos sitúa en un plano de igualdad a los dos grupos mayores, cualquiera que sea el que se oponga al Gobierno, cuyos diputados formularán diez preguntas. 
sucesión de monólogos entre un parlamentario y un ministro ante una Cámara casi desierta.

Podemos intentar que las interpelaciones vuelvan a convertirse en un auténtico debate sobre cuestiones de política general, como las definen los Reglamentos, con intervención de todos los grupos y posible votación de mociones.

Ya no caben malas interpretaciones sobre la trascendencia de una votación, como las que pretendía despejar el art. 111.2 de la Constitución al establecer que toda interpelación podrá dar lugar a una moción en la que la Cámara manifieste su posición, y sabemos que aquella no puede comprometer la responsabilidad del Gobierno, cuyo único cauce a iniciativa parlamentaria es la moción de censura. Carece, pues, de sentido diferir la votación de la moción hasta la siguiente sesión plenaria.

Hoy en día, es evidente que cuando las Cámaras se constituyen en el centro del debate político no es precisamente por el ejercicio de los instrumentos ordinarios de control. Intentemos que las sesiones semanales cumplan con esa función. La inclusión en los Reglamentos de las preguntas al Presidente del Gobierno —introducidas por el uso parlamentario, primero en el Congreso, más tarde en el Senado- y de las interpelaciones también al Presidente del Gobierno en el Congreso de los Diputados, reclamadas por la oposición en las sucesivas reformas del Reglamento proyectadas y no culminadas a lo largo de distintas legislaturas, podrían ayudar a cumplir esa función.

Es frecuente hablar del estatuto constitucional de la oposición ${ }^{51}$ como panacea de todos los males de nuestro sistema parlamentario. Es factible, por ejemplo, la reserva en exclusiva de instrumentos de control y de algún punto en el orden del día ${ }^{52}$, o conseguir que las comisiones de investigación no queden totalmente en manos de la mayoría (en un doble papel de controladora y controlada) en cuanto a creación, plan de trabajo y conclusiones. Se suele citar el ejemplo de las Constituciones alemana y portuguesa ${ }^{53}$ o los más cercanos de Castilla y León y Catalu-

51 Véase Sánchez Navarro, A.: La oposición parlamentaria, Congreso de los Diputados, Madrid, 1997, y Las minorías en la estructura parlamentaria, Centro de Estudios Constitucionales, Madrid, 1995, asi como López Aguilar, J. F.: Minoría y oposición en el parlamentarismo. Una aproximación comparada, Congreso de los Diputados, Madrid, 1991. Para las reformas introducidas en 2008 en la Constitución francesa, los trabajos de SÁnchez Navarro, A.: «Los grupos parlamentarios y la oposición en Francia», y García-Escudero MÁrQueZ, P.: «La revitalización del parlamento en la reforma constitucional francesa de 2008», en Cuadernos de Derecho público n. ${ }^{\circ}$ 34-35, 2008.

52 Véase el ejemplo del art. 176 de la Constitución portuguesa.

53 Art. 44.1 de la Ley Fundamental de Bonn: «El Bundestag tiene el derecho y, a petición de una cuarta parte de sus miembros, el deber de nombrar una Comisión de investigación encargada de reunir las pruebas necesarias en sesiones públicas. Podrá excluirse la presencia de público». Art. 178 de la Constitución de la República portuguesa: «4. Sin perjuicio de su constitución conforme a las condiciones generales, las comisiones parlamentarias de investigación se constituyen obligatoriamente siempre que así se reclame por una quinta parte de los Diputados en el ejercicio efectivo de sus funciones, hasta el límite de una por Diputado y por periodo de sesiones legislativas». 
ña ${ }^{54}$, que dan más oportunidades a la minoría. También puede incluirse en el Reglamento del Congreso de los Diputados una referencia al seguimiento por el Parlamento de sus resoluciones de indirizzo, proposiciones no de ley y mociones; por ejemplo, el informe del Gobierno sobre su cumplimiento, algo que ya existe con una eficacia relativa en el art. 178.2 del Reglamento del Senado respecto de las mociones ${ }^{55}$.

Y aquí también reclamamos algún gesto en favor de los backbenchers o parlamentarios individuales, que les dé voz e identificación frente a la opinión pública. Gozan de este privilegio los miembros del Grupo Mixto cuando son representantes únicos de una formación política, gracias a la posibilidad de intervención en todos los debates plenarios. No, en cambio, los más de cien miembros de los dos grupos mayores, que apenas si formularán alguna pregunta oral ante el Pleno en toda la legislatura.

No olvidemos que las eventuales reformas que dejaran más margen a la oposición deberían ir acompañadas de un uso responsable de las facultades concedidas, que no las utilice con fines exclusivamente demagógicos para desestabilizar al Gobierno, intentando buscar un equilibrio entre un control responsable y un dejarse controlar responsablemente.

A su vez, el «contracontrol» por la mayoría, el uso del «y tú más» como única respuesta a la crítica, es negativo para la visión de la institución parlamentaria por la opinión pública ${ }^{56}$. Pero aquí entramos de nuevo en la realidad política, y la actuación de sus actores no es fácil de cambiar con normas, y mucho menos constitucionales. Aquéllos deben ser conscientes de que el régimen parlamentario es aquel en el que el Gobierno, aparte de contar con la confianza del Parlamento, tiene que gobernar ante él, dando permanentemente cuenta al

54 En Castilla y León (art. 50 del Reglamento de las Cortes), la creación de una Comisión de Investigación puede ser solicitada por la Junta de Castilla y León, por dos grupos parlamentarios o por un quinto de los miembros de las Cortes. Transcurridos quince días desde la fecha de la publicación sin que ningún grupo parlamentario manifieste su oposición, se entenderá creada la Comisión solicitada. Si algún grupo parlamentario manifestase su oposición a la creación de la Comisión, esta se sustanciará ante el Pleno de la Cámara y no se creará la Comisión si se opone la mayoría absoluta de los miembros de la Cámara. Véase también el Reglamento del Parlamento de Cataluña, art. 58.3. «El Parlamento debe crear una comisión de investigación si lo solicitan una tercera parte de los diputados o tres grupos parlamentarios; los proponentes sólo pueden presentar una propuesta vinculante cada año».

55 En este precepto se establece el informe dentro de los seis meses siguiente a la aprobación de la moción, siendo el informe publicado por la Cámara. La obligación de informar podría ser periódica, para el conjunto de iniciativas aprobadas en un período de sesiones, por ejemplo. En el art. 169.4 del Reglamento del Parlamento de Canarias recientemente reformado, se atribuye el control del cumplimiento de la moción a la comisión competente por razón de la materia. El Gobierno de Canarias remitirá un informe sobre las medidas adoptadas o las razones que justifiquen la imposibilidad de cumplirla; si en la moción no se establece plazo, antes de finalizar el periodo de periodos siguiente a la publicación de la moción.

56 También en el Parlamento británico, dice GARTON AsH, T., «Es urgente renovar el Parlamento británico», cit., se ha producido una degradación de la función de control. La sesión semanal de preguntas al Primer Ministro (PMQ) «se ha convertido en una pelea a gritos, propia de un patio de colegio..., sesiones llenas de indignación pero con muy escaso contenido». 
mismo de su actuación, y que esta accountability es la finalidad de los instrumentos de control.

c) Otras funciones parlamentarias necesitadas de renovación

1. Tal vez sea la función financiera de las Cámaras — tan afectada por las recientes circunstancias que han hecho tambalearse nuestro sistema financiero $^{57}$ — la merecedora de un análisis más amplio y sosegado, incluso en el supuesto de una reforma constitucional. Pero su conexión con las consecuencias de nuestra pertenencia a la Unión Europea y la técnicamente no muy afortunada (en cuanto a su procedimiento y resultado) reforma del art. 135 , que por sí sola ha sido objeto de especial atención ${ }^{58}$, hacen que sea más adecuado un tratamiento detenido en otro lugar.

Apuntaremos sólo la conveniencia de articular nuevos procedimientos de debate y control real, en los que el Tribunal de Cuentas debería jugar un papel de mayor efectividad que hasta ahora. No olvidemos que se trata de un órgano dependiente y delegado de las Cortes Generales, al menos en el diseño constitucional.

2. También ha experimentado una transformación considerable la función de las Cortes Generales en materia internacional, y no sólo como consecuencia de nuestra pertenencia a la Unión Europea, sino también a causa de los compromisos derivados de nuestra relación con otros organismos internacionales, de la evolución que han experimentado los conflictos y de la globalización.

Está claro que el escenario ha cambiado desde 1978 y que a la luz de estos cambios debería replantearse la intervención del poder legislativo, en un ámbito cada vez más claramente propio del Ejecutivo.

57 Incluso desde antes, véanse las competencias en relación con la aprobación del objetivo de estabilidad presupuestaria establecido por la Ley 18/2001, de 12 de diciembre, general de estabilidad presupuestaria. En la Ley Orgánica 2/2012, de 27 de abril, de estabilidad presupuestaria y sostenibilidad financiera, que desarrolla el nuevo art. 135 de la Constitución, se regula la competencia del Congreso para autorizar el déficit estructural en situaciones extraordinarias (art. 11), la autorización por ley al Estado y las Comunidades Autónomas para emitir deuda pública o contraer crédito (art. 13), la aprobación por las Cortes Generales de los objetivos de estabilidad presupuestaria y deuda pública (art. 15.6) y del plan económico-financiero y el plan de reequilibrio de la Administración Central (art. 23.2), además del eventual recurso al art. 155 de la Constitución, con la aprobación de la mayoría absoluta del Senado, para adoptar medidas de cumplimiento forzoso para las Comunidades Autónomas (art. 26).

58 Puede verse GArcía-Escudero Márquez, P.: «La acelerada tramitación parlamentaria de la reforma del art. 135 de la Constitución (Especial consideración de la inadmisión de enmiendas. Los límites al derecho de enmienda en la reforma constitucional)», Teoría y Realidad Constitucional, n. ${ }^{\circ} 29,2012$, pp. 165-198, y «Sobre la reforma del art. 135 de la Constitución», Crónica presupuestaria, n. ${ }^{\circ}$ 1, 2013, pp. 94-105, así como García Roca, J. y Martínez Lago, M. A.: Estabilidad presupuestaria y consagración del freno constitucional al endeudamiento, Civitas-Aranzadi, Cizur Menor, 2013. 
Además de revisar en una eventual reforma constitucional la redacción del art. 63 — autorización de las Cortes Generales al Rey para declarar la guerra y hacer la paz, los conflictos armados hoy no se declaran formalmente-, podría incluirse en la Constitución (como ocurre en la france$\mathrm{sa}^{59}$ ) la autorización del Congreso para el envío de tropas al exterior, regulada por la Ley Orgánica 5/2005, de 17 de noviembre, de Defensa Nacional (vid. arts. 17, autorización, y 18, seguimiento de las operaciones), y que merecería en el texto constitucional al menos una remisión a la ley y a las obligaciones derivadas de nuestros compromisos con organizaciones internacionales, asimismo contempladas en la Ley Orgánica (art. 19) como condición para las misiones en el exterior.

También podría ser objeto de una revisión actualizada el art. 93 de la Constitución, concebido y ratificado por el Tribunal Constitucional ${ }^{60}$ como bisagra que da paso al ordenamiento comunitario, que incluyera una referencia a nuestra pertenencia a la Unión Europea ${ }^{61}$ y prestara especial atención al inciso relativo al cumplimiento de los tratados a la luz del Estado autonómico.

Las comparecencias del Presidente de Gobierno ante el Pleno del Congreso de los Diputados para debatir sobre los asuntos tratados en los Consejos Europeos ${ }^{62}$ se han convertido en un formulismo más, cuando deberían constituir uno de los hitos de la participación del Parlamento español en las políticas de la Unión Europea: esforcémonos por realizar debates con sentido y relevancia. Asimismo, puede sacarse partido a las nuevas competencias de la Comisión Mixta para la Unión Europea, añadidas por la Ley 38/2010, de 20 de diciembre: comparecencias periódicas del Gobier-

59 Art. 35 Constitución francesa: «La declaración de guerra será autorizada por el Parlamento.//El Gobierno informará al Parlamento sobre su decisión de hacer intervenir a las fuerzas armadas en el extranjero, a más tardar tres días después del inicio de la intervención. Concretará los objetivos perseguidos. Esta información podrá dar lugar a un debate que no será objeto de ninguna votación.//Cuando la duración de la intervención exceda de cuatro meses, el Gobierno someterá su prolongación a la autorización del Parlamento. Podrá pedir a la Asamblea Nacional que decida en última instancia.//Si el Parlamento no está en período de sesiones al vencimiento del plazo de cuatro meses, se pronunciará a la apertura del siguiente período de sesiones».

60 Véanse las Declaraciones del Tribunal Constitucional sobre la constitucionalidad de determinadas disposiciones del Tratado de Maastricht (Decl. 1/1992, especialmente FJ 4) y del Tratado por el que se establece una Constitución para Europa (Decl. 1/2004, en particular FJ 2).

61 Pueden verse las propuestas del Consejo del Estado en el Informe sobre modificaciones de la Constitución española, en Rubio Llorente, F. y Alvarez Junco, J. (ed.): El Informe del Consejo de Estado sobre la reforma constitucional. Texto del Informe y debates académicos, Centro de Estudios Políticos y Constitucionales, Madrid, 2006, esp. p. 109 y ss. El Consejo de Estado opta por la inclusión de un nuevo Título en la Constitución, en lugar de un art. 93 bis.

62 De conformidad con el art. 4 de la Ley 8/1994, de 19 de mayo, por la que se regula la Comisión Mixta para la Unión Europea, el Gobierno comparecerá ante el Pleno del Congreso de los Diputados, con posterioridad a cada Consejo Europeo, ordinario y extraordinario, para informar sobre lo allí decidido y mantener un debate con los grupos parlamentarios. 
no a la vista del calendario de reuniones semestrales del Consejo, para manifestar la posición del Gobierno en relación con los asuntos incluidos en el orden del día, y al final de cada presidencia semestral, y comparecencias de miembros de los Gobiernos de las Comunidades Autónomas (nuevos arts. 8 a 10 de la Ley 8/1994, de 19 de mayo, por la que se regula la Comisión Mixta para la Unión Europea).

3. En cuanto a la función de integración de órganos por el Parlamento, es de todos sabida la problemática que ha rodeado esta función en los años de vigencia de la Constitución, hasta el punto de considerarse una de las causas que inciden en el descrédito de las instituciones integradas y de las Cámaras que los nombran. Como escribía en otro lugar ${ }^{63}$, la consecuencia inmediata de la atribución al Parlamento de la designación de titulares de cargos o miembros de órganos colegiados es la politización de estos nombramientos. El Parlamento es un órgano político, sus decisiones son decisiones políticas y sus actores, parlamentarios y grupos — trasunto de los partidos-, se mueven por criterios de esta naturaleza. Ello da lugar a que los mecanismos de integración de órganos previstos constitucional o legalmente no siempre funcionen correctamente, produciéndose desviaciones y bloqueos.

No voy a extenderme aquí en lo analizado con detalle en aquel trabajo, donde se exponen los males (mayorías cualificadas: del consenso a las cuotas por partidos; la falta de consenso: bloqueos institucionales) y sus intentos de remedio legislativo, del que el más sangrante, como muestra de que puede alterarse todo varias veces para llegar al mismo resultado, es el repetido cambio en la regulación legal del nombramiento de los miembros del Consejo General del Poder Judicial, el último por Ley Orgánica 4/2013, de 28 de junio, que introduce un nuevo Libro VIII en la Ley Orgánica 6/1985, de 1 de julio.

No es tanto el ordenamiento jurídico-constitucional el causante de todos los males: el defectuoso funcionamiento del sistema de integración de órganos por las Cortes Generales deriva de la actuación de los partidos políticos y no es fácil luchar contra la realidad. Se ha apuntado la posibilidad de excluir de los candidatos a miembros del Consejo General del Poder Judicial a personas que hubieran desempeñado cargos de militancia política (diputado, senador). La regeneración ha de venir de nuevo más bien de la voluntad política, haciendo realidad lo que afirmaba el Tribunal Constitucional en su sentencia 108/1996

63 García-Escudero Márquez, P.: «La problemática de la integración de órganos por el Parlamento», Asamblea, n. ${ }^{\circ}$ 27, 2012, p. 12. Puede verse también Santaolalla, F. y Pauner Chulvi, C.: Procedimientos de designación parlamentaria de cargos públicos, Centro de Estudios Políticos y Constitucionales, Madrid, 2010, y García Roca, J.: «La selección de los magistrados constitucionales, su estatuto y la necesaria regeneración de las instituciones», Revista General de Derecho Constitucional, n. ${ }^{\circ} 15,2012$, quien formula algunas propuestas. 
(FJ 13), en recurso contra la Ley Orgánica 6/1985, de 1 de julio, del Poder Judicial, que atribuyó a las Cámaras el nombramiento de la totalidad de los miembros del Consejo: «La lógica del Estado de partidos empuja a actuaciones de este género [frustrar la finalidad señalada de la norma constitucional si las Cámaras, a la hora de efectuar sus propuestas, olvidan el objetivo perseguido y, actuando con criterios admisibles en otros terrenos, pero no en este, atienden solo a la división de fuerzas existente en su propio seno y distribuyen los puestos a cubrir entre los distintos partidos, en proporción a la fuerza parlamentaria de estos], pero esa misma lógica obliga a mantener al margen de la lucha de partidos ciertos ámbitos de poder y entre ellos, y señaladamente, el Poder Judicial». Esto sería aplicable también al Tribunal Constitucional, el Tribunal de Cuentas y otros ámbitos.

Son asimismo los propios actores políticos los que deben otorgar sentido a aquellas normas que pretenden dotar de mayor legitimidad democrática o de independencia del Ejecutivo a los miembros de determinados órganos, en particular las llamadas Administraciones independientes que han proliferado en los últimos tiempos, altos órganos de control de determinados sectores (mercado de valores, comunicaciones, radiotelevisión pública) en la designación de cuyos miembros participan de alguna forma ${ }^{64}$ las Cámaras precisamente para dotarles de ese carácter.

Las comparecencias previas ante comisiones de las Cámaras, o la obtención de su parecer favorable se han desarrollado casi como una pantomima carente de objeto, una mera formalidad que cumplimentar. $\mathrm{O}$ se recupera el sentido de esta intervención parlamentaria, o es casi mejor que se suprima.

\section{LA TRANSPARENCIA PARLAMENTARIA}

\section{Publicidad y transparencia}

Al abordar el tema de la transparencia parlamentaria, tan en boga hoy en día como medio para la regeneración de las instituciones y la recuperación de su

64 La Ley 5/2006, de 10 de abril, de regulación de los conflictos de intereses de los miembros del Gobierno y de los altos cargos de la Administración General del Estado (arts. 2 y 3 ) estableció la comparecencia ante la Comisión correspondiente del Congreso de los Diputados de España previa al nombramiento por el Gobierno del Presidente del Consejo de Estado o de los máximos responsables de los organismos reguladores o de supervisión, entre otros cargos. Esta norma ha sido sustituida por la disposición adicional tercera de la Ley 3/2015, de 30 de marzo, reguladora del ejercicio del alto cargo en la Administración General del Estado, según la cual la Comisión emitirá un dictamen en el que se pronunciará sobre si se aprecia la idoneidad del candidato propuesto o la existencia de conflicto de intereses. Son numerosas las leyes reguladoras de órganos respecto de cuya integración o designación de cargos prevén la comparecencia ante una Comisión o la expresión de criterio por la misma. 
prestigio $^{65}$, podemos partir de una afirmación políticamente incorrecta: el Parlamento es la institución más transparente en la toma de decisiones ${ }^{66}$.

En efecto, recuérdese que la deliberación y la publicidad son elementos inherentes al procedimiento legislativo ${ }^{67}$ y que luz y taquígrafos son consustanciales al Parlamento democrático desde su proclamación por la Constitución francesa de 1791: «las deliberaciones del Cuerpo legislativo serán públicas y las actas de las sesiones se imprimirán». El principio de publicidad pasaría a la Constitución de Cádiz, cuyo art. 126 (Las sesiones de las Cortes serán públicas, y sólo en los casos que exijan reserva podrá celebrarse sesión secreta ${ }^{68}$ ) se mantiene en el art. 80 de la vigente referido a las sesiones plenarias.

En el mismo sentido, citaremos la STC 136/1989: «La publicidad parlamentaria, que es una exigencia del carácter representativo de los electores, ofrece dos vertientes: una, la publicidad de las sesiones; otra, la publicación de las deliberaciones y de los acuerdos adoptados».

En el plano de la realidad, no obstante, hemos de reconocer la desvirtuación de la toma de decisiones parlamentarias en el actual Estado de partidos (predominio del Ejecutivo, disciplina de voto) y la extraparlamentarización de la negociación, en consecuencia no transparente por desarrollarse en el preproceso legislativo, en que se determina de antemano el contenido de la ley o de la votación.

\section{Transparencia parlamentaria}

El Parlamento debe acoger lo que de regenerador tiene el movimiento por la transparencia de las instituciones plasmado en la Ley 19/2013, de 9 de diciembre, de transparencia, acceso a la información pública y buen gobierno ${ }^{69}$, cuyo

65 Transparencia es una de las palabras clave del discurso político actual, recuerda SAINz Moreno, F. ( «ecreto y transparencia, en Estudios para la reforma de la Administración Pública, Instituto Nacional de Administración Pública, Madrid, 2004, p. 165), como hace pocos años lo fue la participación, que tanta euforia produjo. La democracia exige un incesante proceso hacia la máxima transparencia de la Administración. Sobre el concepto y la evolución de la transparencia, y las causas de su fuerte emergencia puede verse CotiNO, L., Teoría y realidad de la transparencia pública en Europa, versión electrónica 2003, p. 7 y ss.

66 La transparencia, como indica GALlardo CASTILlo, M.J., «Transparencia, poder público y derecho a la información», Cuadernos M. Giménez Abad, n. ${ }^{\circ}$ 8, 2014, p. 159 y ss., es una cualidad inherente a todo proceso decisorio, un parámetro que debe informar la actuación administrativa, que fortalece la seguridad jurídica de los ciudadanos, que imprime racionalidad al proceso de toma de decisiones y que dota de legitimidad a la decisión misma por cuanto facilita su aceptación y engendra un mayor entendimiento. El principio de transparencia se ha convertido en una precondición de la propia democracia y arquetipo y pilar fundamental del Estado democrático y del Estado de Derecho.

67 Hasta el punto de que el art. 85.1 del Reglamento del Congreso de los Diputados prohíbe la votación secreta en los procedimientos legislativos.

68 Compárese el art. 126 de la Constitución gaditana con el 80 de la Constitución de Bayona, según el cual «las sesiones de las Cortes no serán públicas». Obviamente, ni los autores ni la filosofía inspiradora eran los mismos.

69 Un análisis de esta Ley en el marco más amplio del Gobierno abierto, en Rubio, R., «Gobierno y gobernanza, hoy», en Nueva Revista n. ${ }^{\circ} 145,2013$, p. 2 y ss. Sobre la Alianza para el Gobierno abierto consti- 
Título I (publicidad activa en páginas web y publicidad pasiva o derecho de acceso a la información), por disposición del art. 2.1.f se aplica al Congreso de los Diputados, al Senado y a los Parlamentos autonómicos, en relación con sus actividades sujetas al Derecho administrativo.

Si bien la disposición adicional octava remite a los respectivos Reglamentos la aplicación concreta de las disposiciones de la Ley, la debida autonomía parlamentaria nunca podría ser excusa para el incumplimiento de una normativa que entró en vigor, conforme a su disposición final novena, el 10 de diciembre de 2014, aunque los órganos de las Comunidades Autónomas y entidades locales disponen de un año más para adaptarse a las obligaciones contenidas en la Ley.

Podemos afirmar que en el órgano legislativo suele existir desde hace tiempo transparencia absoluta en lo que a la actividad parlamentaria se refiere ${ }^{70}:$ los Reglamentos regulan la publicidad de las sesiones y trabajos parlamentarios a través de los Diarios de Sesiones y Boletines Oficiales, a los que se han unido más tarde los canales parlamentarios y las páginas web.

En dos direcciones puede extenderse todavía la transparencia de nuestras Cámaras:

- hacia el llamado Parlamento abierto ${ }^{71}$, que busca una relación bidireccional con el pueblo, aprovechando las nuevas tecnologías de la información que permiten una interacción que fomente la transparencia y la rendición de cuentas, con el objetivo final de combatir la desafección ciudadana y la desconfianza hacia los políticos. A esta cuestión vamos a dedicar el apartado siguiente de este estudio.

- en la transparencia en la gestión de recursos, mediante el acceso a información hasta ahora no publicada, que no está relacionada con las funciones constitucionales de las Cámaras, sino con su funcionamiento económico-administrativo como órgano (contratos, presupuestos, personal) y con sus miembros (retribuciones, intereses..., información que ya es pública).

El Informe GRECO ${ }^{72} 2013$ sobre España, publicado en enero de 2014, reconoce las medidas positivas adoptadas para asegurar la transparencia en el procedimiento legislativo y recomienda mejorar la publicidad de los antecedentes, la

tuida en 2011 en Nueva York por 47 países, entre ellos España, ECHART, N., «Hacia un modelo de democracia más participativa», en la misma revista, p. 13 y ss.

70 En el Índice a que aludiremos a continuación, el Congreso, el Senado y seis Parlamentos autonómicos obtienen $100 \%$ en el área de información sobre el funcionamiento y la actividad parlamentaria, siendo sólo tres los que obtienen una calificación inferior al $50 \%$.

71 Puede verse al respecto Gutiérrez-Rubí, A.: «Parlamento abierto y política de proximidad», y Rubio NúÑEZ, R.: «Knocking on the Parliaments door (Parlamentos digitales en la era de la participación)», ambas en Parlamentos y redes para la democracia, Rubio NúÑEZ, A. (coord.), Congreso de los Diputados, Madrid, 2014, p. 363 y ss.

72 Grupo de Estados contra la corrupción, en el marco del Consejo de Europa. 
agenda de los parlamentarios y sus contactos con lobbyistas y terceros, la actualización y el detalle de sus declaraciones, el preproceso legislativo y la información pública de los proyectos de ley, así como mejorar la cultura de la ética de los parlamentarios y la adopción de un código ético.

Este Informe indica que, para restaurar la imagen de los políticos y volver a captar la confianza pública, las Cámaras deben continuar buscando vías para promover una cultura de la honradez (integrity) de sus miembros, que va más allá de mecanismos de rendición de cuentas o accountability. Para apoyar y fortalecer la confianza pública en el Parlamento, considera indispensable que se hagan llegar al pueblo las medidas adoptadas para reforzar la ética de los parlamentarios, para incrementar la transparencia y establecer una rendición de cuentas efectiva ${ }^{73}$.

En otra evaluación relevante, el primer índice de transparencia de los Parlamentos (IPAR), realizado a los 19 Parlamentos españoles en 2013-2014 por la organización Transparencia Internacional ${ }^{74}$, los resultados no han sido en absoluto negativos $^{75}$. Esta primera evaluación, realizada sobre 80 indicadores divididos en seis áreas de transparencia, revela un cumplimiento casi pleno de los indicadores relativos a información sobre funcionamiento y actividad parlamentaria y relaciones con los ciudadanos y la sociedad. Queda pendiente de mejora la transparencia económico-financiera, que avanzará con la entrada en vigor de la Ley 19/2013.

Hay que seguir perseverando en el objetivo final de la transparencia como instrumento regenerador de la confianza y del crédito de las instituciones, y potenciar la rendición de cuentas ${ }^{76}$. En esta perspectiva, no obstante, ha de tenerse siempre en

73 En este sentido, cabe destacar que, como como consecuencia de la aparición de un supuesto concreto en los medios de comunicación, las Mesas del Congreso y del Senado acordaron con gran rapidez aprobar y hacer públicas unas normas sobre los desplazamientos de los parlamentarios. Véanse Resolución de la Presidencia del Congreso de los Diputados y Acuerdo de la Mesa del Senado, ambos de 18 de noviembre de 2014 (y de contenido similar), en materia de control y publicidad de los desplazamientos de los diputados y senadores, BOCG Congreso n. ${ }^{\circ}$ 562, 19 noviembre 2014, y Senado n. ${ }^{\circ} 440,20$ noviembre, respectivamente.

74 Sobre los fines y labor realizada por TI en los Índices de transparencia de las Administraciones Públicas, véase Lizcano Alvarez, J. (Presidente de TI España), «Transparencia Internacional España ¿qué es? ¿qué hace?», en Tiempo de Paz n. ${ }^{\circ} 114,2014$, p. 25 y ss.

75 Como puede verse en http://www.transparencia.org.es/IPAR/Resultados_IPAR.pdf, la organización valora positivamente los resultados obtenidos en esta primera evaluación, superiores a los realizados a otras instituciones. A nivel de valoración global, hay dieciséis Parlamentos que han superado los 50 puntos sobre 100, quedando sólo tres instituciones parlamentarias por debajo de este umbral. En lo relativo a las seis áreas de transparencia evaluadas, sólo una de ellas, la transparencia económica-financiera, presenta una media inferior (49²), mientras que en tres áreas la nota media es superior: transparencia en las contrataciones de servicios $\left(51^{\prime} 2\right)$, indicadores de las nueva Ley de Transparencia $\left(58^{\prime} 6\right)$ y relaciones con los ciudadanos y la sociedad (63'2), alcanzando una nota media superior al $70 \%$ en las dos áreas restantes: información sobre el Parlamento (73’2) e información sobre el funcionamiento y la actividad parlamentaria (81’4).

76 Como dice Greciet, E.: «Un Parlamento diferente», cit., una concepción clásica de la publicidad parlamentaria debe ser completada y aun superada por otra que haga de la institución el verdadero «centro de transparencia» de toda la información y documentación de interés público, universalmente accesible sin merma de su detalle técnico, y vinculada a cuantas iniciativas al respecto surjan de los diputados y de los grupos políticos. «El Parlamento se juega mucho en ello: la recuperación de su razón de ser como gozne entre sociedad y Estado, como mediador entre el ciudadano y el Gobierno; pero puede y debe llevarlo a cabo de la mano 
cuenta al hablar de transparencia parlamentaria que el Parlamento es una institución de pequeño tamaño y que, incluso en sus actos administrativos, se trataría de una Administración sui generis — sin relaciones con los particulares-, cuyos actos están sujetos a control jurisdiccional (constitucional, el ejercicio de sus funciones parlamentarias; contencioso-administrativo, los actos de administración y personal). También debe recordarse que la credibilidad de la transparencia de la institución parlamentaria depende en gran medida de la que tengan los grupos parlamentarios y las propias formaciones políticas que en ella se integran.

Terminemos este epígrafe reafirmando y reclamando la centralidad del Parlamento como órgano representativo de la soberanía, centralidad que debe ganarse en su día a día, y la necesidad de aprovechar las herramientas tecnológicas para reforzar la representación política a través de vínculos de información y participación ${ }^{77}$. El equilibrio entre la transparencia y el eficaz cumplimiento de la función representativa es uno de los retos con los que se enfrenta el Parlamento del siglo XXI.

\section{Aplicación de la Ley 19/2013 a las Cámaras}

La Ley 19/2013, de Transparencia, acceso a la información pública y buen gobierno, se estructura en dos títulos, relativos respectivamente a la transparencia de la actividad pública y al buen gobierno, dividido el primero de ellos en dos grandes bloques: la publicidad activa y el derecho de acceso a la información pública.

En el ámbito de aplicación del Título I (Transparencia de la actividad pública, arts. 2 a 24) definido en el art. 2.1, se incluyen expresamente (f) el Congreso de los Diputados y el Senado (no las Cortes Generales), junto a la Casa de Su Majestad el Rey, los organismos constitucionales (Tribunal Constitucional, Consejo General del Poder Judicial) y de relevancia constitucional (Consejo de Estado, Defensor del Pueblo, Tribunal de Cuentas, Consejo Económico y social), el Banco de España y las instituciones autonómicas análogas, todos ellos en relación con sus actividades sujetas a Derecho administrativo ${ }^{78}$.

de las tecnologías de la comunicación y al hilo de las experiencias participativas que logre activar. La información económico-financiera, la ejecución del gasto o la evaluación de las políticas públicas son sólo tres de los campos en que urge que lo anterior se ponga en marcha».

77 Sobre las consecuencias de las nuevas tecnologías en la propia institución parlamentaria, puede verse Tudela Aranda, J.: «Parlamento y nuevas tecnologías», en El Parlamento del siglo XXI. VIII Jornadas de la Asociación Española de Letrados de Parlamentos, Tecnos, Madrid, 2002, p. 105 y ss.

78 Como afirma Ruiz-Rico Ruiz, C., «El poder parlamentario y sus límites: conflicto de intereses, extralimitaciones y transparencia», Cuadernos Manuel Giménez Abad n. ${ }^{\circ}$ 8, 2014, quiebra el principio hasta ahora integral de la autonomía parlamentaria, legislativa y presupuestaria, pues el control legal derivado de la publicidad activa en las actuaciones sujetas a Derecho Administrativo puede repercutir paralelamente en las autonomías presupuestaria y legislativa, dado que la autonomía administrativa es puramente instrumental respecto de la autonomía parlamentaria; el difícil deslinde entre autonomía legislativa y administrativa se manifiesta a nivel documental en la no siempre fácil delimitación entre documento parlamentario y otros documentos gestionados por los servicios administrativos de la institución que se englobarían también en la documentación parlamenta- 
Las obligaciones contenidas en el Título I se refieren básicamente a:

— la publicidad activa (Capitulo II), consistente en la obligación de publicar de forma periódica y actualizada la información cuyo conocimiento sea relevante para garantizar la transparencia de su actividad relacionada con el funcionamiento y control de la actividad pública, entendiéndose las obligaciones impuestas en el capítulo de publicidad activa sin perjuicio de la aplicación de otras disposiciones específicas que prevean un régimen más amplio en materia de publicidad.

- el derecho de acceso a la información pública (Capítulo III), esto es a los contenidos o documentos, cualquiera que sea su formato o soporte, que obren en poder de alguno de los sujetos incluidos en el ámbito de aplicación del Título I y que hayan sido elaborados o adquiridos en el ejercicio de sus funciones. La Ley regula los límites y el ejercicio del derecho de acceso, así como el régimen de impugnaciones.

El Título II, relativo al Buen Gobierno (arts. 25 a 32) es de aplicación, de conformidad con su art. 25, a los altos cargos de la Administración General del Estado y de las entidades del sector público estatal, de derecho público o privado, vinculadas o dependientes de aquella (considerándose a estos efectos altos cargos los previstos en el normativa en materia de conflictos de intereses), así como a los altos cargos o asimilados que, de acuerdo con la normativa autonómica o local que sea de aplicación tengan tal consideración. No son por tanto las disposiciones del título relativo al buen gobierno aplicables a las Cámaras que integran las Cortes Generales ni a los Parlamentos autonómicos.

Es importante reiterar que, a los efectos de salvaguardar la autonomía parlamentaria, la disposición adicional octava establece que el Congreso de los Diputados, el Senado y las Asambleas Legislativas de las Comunidades Autónomas regularán la aplicación concreta de las disposiciones de la Ley ${ }^{79}$. Ello supone, pues, que ésta no es de aplicación directa en el caso de las instituciones parlamentarias, sino que requiere una regulación propia de cada Cámara, que estudiamos a continuación.

Por otra parte, la normativa parlamentaria en materia de transparencia y acceso a la información no comienza a partir de la Ley $19 / 2013^{80}$. Sirvan de ejemplo los

ria. De hecho, las evaluaciones de transparencia no se limitan a la actividad administrativa, sino que efectúan una valoración global de la transparencia en los distintos ámbitos de la autonomía parlamentaria.

79 Este precepto no figuraba en el Proyecto de ley remitido por el Gobierno al Congreso de los Diputados, véase BOCG Congreso n. ${ }^{\circ}$ 19-1, 7 septiembre 2012. Fue introducido por la Comisión Constitucional del Congreso mediante la aprobación de una enmienda transaccional a la enmienda n. ${ }^{\circ} 42$ del Grupo Catalán $(\mathrm{CiU})$, cuyo texto era el siguiente: «Disposición adicional. El Congreso de los Diputados, el Senado y las Asambleas Legislativas de las Comunidades Autónomas definirán a través de sus respectivos reglamentos la aplicación concreta en sus instituciones de las disposiciones de esta ley.»

80 Sobre la transparencia parlamentaria, puede verse GonZALO, M.A., «Transparencia en los Parlamentos», Tiempo de Paz n. ${ }^{\circ} 114,2014$, p. 49 y ss. 
acuerdos de las Mesas del Congreso de los Diputados y el Senado de 21 de diciembre de 2009 (BOCG n. ${ }^{\circ} 247$, 14 enero 2010), por el que se aprueban normas en materia de registro de intereses, y de 19 de julio de 2011 (BOCG n. ${ }^{\circ}$ 455, 22 julio 2011), que modifica el anterior ${ }^{81}$. En ellos se establece la publicidad en la sede electrónica de cada Cámara de los Registros de actividades, y posteriormente de bienes, de los parlamentarios, en un formato que no sea susceptible de manipulación por terceros.

a) Senado

Como se ha señalado, la disposición final novena de la Ley 19/2013 fija la entrada en vigor de su Título I (junto con el Título preliminar y el III) al año de su publicación en el Boletín Oficial del Estado, que tuvo lugar el 10 de diciembre de 2013.

La reforma del Reglamento del Senado aprobada por el Pleno el 5 de junio de 2014 incluye en el art. 36.1, relativo a las competencias de la Mesa de la Cámara, la de «aprobar las normas y adoptar las medidas que resulten precisas para garantizar la transparencia de la actividad de la Cámara y el derecho de acceso a la información pública del Senado» ${ }^{82}$.

El 9 de diciembre de 2014, es decir el día anterior al señalado para la entrada en vigor del Título I de la Ley 19/2013, se publica en el Boletín Oficial de las Cortes Generales ${ }^{83}$ la Norma reguladora del derecho de acceso a la información pública del Senado, aprobada por la Mesa de esta Cámara el 2 de diciembre. Esta Norma, de conformidad con su disposición final segunda, entró en vigor el día 10 de diciembre de 2014, por tanto simultáneamente a la Ley de Transparencia.

Las especialidades más relevantes respecto a la regulación general son las siguientes $^{84}$ :

- El órgano competente para resolver las solicitudes de acceso a la información pública es la Mesa del Senado. No obstante, cuando la información estuviese publicada en la web del Senado, las solicitudes serán contestadas por las unidades de información de la Secretaría General con competencia en la materia.

81 A este respecto, conviene recordar que el Informe GRECO 2013 recomienda que se revisen los actuales formularios de declaración aplicables a los miembros de ambas Cámaras del Parlamento a fin de incrementar las categorías y el nivel de detalle de la información, así como que se tomen medidas adecuadas para garantizar una eficaz supervisión y un control del cumplimiento tanto de los requisitos de declaración ya existentes como de aquellos aún por establecer, así como de las demás normas de conducta de los parlamentarios.

82 BOCG Senado n. ${ }^{\circ} 362,9$ junio 2014.

83 BOCG Senado n. ${ }^{\circ} 451,9$ diciembre 2014 , p. 369 y ss.

84 Los requisitos, límites y tramitación de la solicitud son similares a las establecidas para la Administración pública en la Ley 19/2013 (que se aplica, por otra parte con carácter supletorio), incluido el plazo de un mes para la notificación de la resolución que conceda o deniegue el acceso al solicitante y a los terceros afectados, ampliable por otro mes, previa notificación, cuando el volumen o complejidad de la información que se solicita lo haga necesario, así como el acceso preferente por vía electrónica. 
— Los solicitantes de información podrán dirigirse al Senado en cualquier lengua que, con el castellano, tenga el carácter de oficial en alguna Comunidad Autónoma.

- Se añade una causa de inadmisión a trámite de la solicitud a las previstas en el art. 18 de la Ley: que contenga expresiones indecorosas contra personas o contra instituciones, así como meros juicios de valor u opiniones.

- La Secretaría General del Senado adoptará las medidas necesarias para la gestión de las solicitudes de información. El órgano encargado de la coordinación de las distintas unidades que pueden conocer de ellas es la Dirección de Relaciones Institucionales.

El régimen de impugnaciones es, obviamente, el que ofrece mayores variaciones con el establecido por la Ley, puesto que la autonomía parlamentaria impide someter las reclamaciones y recursos a órganos administrativos, como es el Consejo de Transparencia y Buen Gobierno que aquélla crea.

Las resoluciones expresas o presuntas en materia de acceso a la información sobre la actividad del Senado sujetas al Derecho Administrativo son recurribles, previo recurso potestativo ante la Mesa del Senado en el plazo de un mes desde la notificación o el silencio, ante la Sala de lo Contencioso-administrativo del Tribunal Supremo en el plazo de dos meses.

El plazo máximo para resolver el recurso por la Mesa es de tres meses, transcurrido el cual el recurso se entenderá desestimado. Las resoluciones se publicarán, previa disociación de los datos de carácter personal que contuvieran, en la web del Senado, en los términos que establezca la Mesa de la Cámara.

\section{b) Congreso de los Diputados}

En el Congreso de los Diputados, la Mesa, oída la Junta de Portavoces y al amparo de las facultades que le reconoce el art. 31.1.1. ${ }^{\circ}$ del Reglamento para adoptar cuantas decisiones y medidas requieran la organización del trabajo y el régimen y gobierno interiores de la Cámara ${ }^{85}$, aprobó en su reunión del día 20 de enero de 2015 las Normas para la aplicación de las disposiciones de la Ley 19/2013, de 9 de diciembre, de transparencia, acceso a la información pública y buen gobierno a la Cámara, en relación con su actividad sujeta a derecho administrativo ${ }^{86}$.

85 El preámbulo de las Normas considera estas medidas necesarias para la aplicación de la Ley 19/2013, «sin perjuicio de los trabajos que se están desarrollando en la Ponencia para el estudio de una reforma amplia del Reglamento del Congreso de los Diputados». De esta manera se explica el que no se dé cumplimiento a lo establecido en la disposición adicional octava de la Ley, que remite la regulación a los Reglamentos parlamentarios. Dada la complejidad política que entraña cualquier reforma del Reglamento del Congreso de los Diputados, otras remisiones legales en materia diversa han quedado también sin cumplimentación, véase por ejemplo el art. 29.2 de la Ley 50 /1981, de 30 de diciembre, del Estatuto Orgánico del Ministerio Fiscal, en su redacción modificada por la Ley 24/2007, sobre comparecencia previa al nombramiento del Fiscal General del Estado.

86 BOCG Congreso de los Diputados, n. ${ }^{\circ} 595,23$ enero 2015. 
Estas Normas tienen un objeto más amplio que las de la Cámara Alta, por cuanto no sólo regulan el derecho de acceso a la información, sino también la publicidad activa, dedicando su Capítulo II al Portal de Transparencia del Congreso de los Diputados, que ya se había puesto en marcha en el Senado ${ }^{87}$. La Mesa de la Cámara será el órgano encargado de definir y supervisar los contenidos de la información y la Secretaría General adoptará las medidas necesarias para la puesta en marcha y mantenimiento del Portal ${ }^{88}$. Las Normas establecen la información mínima, de acuerdo con lo dispuesto en la Ley 19/2013, así como los principios técnicos de accesibilidad, interoperabilidad y reutilización, cuya aplicación al Portal se adaptará a las posibilidades técnicas existentes en cada momento.

En cuanto al derecho de acceso a la información pública:

- El órgano competente para resolver las solicitudes de acceso a la información es el Secretario General, a propuesta de la Dirección de Documentación, Biblioteca y Archivo. No obstante, la Dirección de Comunicación de la Secretaría General contestará las consultas de información que no susciten dudas o cuando dicha información estuviese publicada en la web del Congreso, sin que en ese caso las contestaciones puedan considerarse incluidas en el procedimiento regulado en las Normas.

- La Secretaría General facilitará un formulario electrónico que permita la presentación de las solicitudes.

- Se incluye la misma causa de inadmisión que en el Senado, relativa a las solicitudes que contengan expresiones indecorosas contra personas o contra instituciones, así como meros juicios de valor u opiniones.

- Se crea una Comisión de Acceso a la Información Pública del Congreso, integrada por los Secretarios Generales Adjuntos para Asuntos Parlamentarios y para Asuntos Administrativos, los Directores de Asistencia Técnico-parlamentaria, de Comunicación y de Documentación, Biblioteca y Archivo, y el funcionario responsable de la unidad que gestione los contenidos del Portal de Transparencia, que actuará como Secretario. Esta Comisión tiene funciones asesoras y de informe, estando facultada para proponer a la Mesa del Congreso la adopción de criterios, recomendaciones, directrices o guías de buenas prácticas en materia de transparencia y acceso a la información del Congreso, que tras su aprobación, serán publicadas en el Boletín Oficial de las Cortes Generales. La Comisión elaborará un informe anual de actividades que elevará a la Mesa. La función principal de la Comisión es elaborar, cuando se solicite, un informe sobre las propuestas de resolución sobre las solicitudes que puedan incurrir en alguno de los supuestos de denegación.

87 En el Índice de Transparencia de 2013, el Senado obtuvo el tercer puesto, con una puntuación de 83,8\%. 88 La Mesa aprobó un Anexo sobre la estructura y contenido iniciales del Portal de transparencia, que puede verse en http://www.congreso.es/portal/page/portal/Congreso/Congreso/Transparencia. El Portal del Congreso se abrió en la página web del Congreso el 26 de febrero de 2015. 
En la medida en que la resolución de las solicitudes se encomienda al Secretario General y no a la Mesa, a diferencia del Senado, varía el régimen de impugnaciones respecto de esta Cámara, estableciéndose el recurso ante la Mesa frente a las resoluciones del Secretario General en el plazo de un mes desde la notificación, si fueran expresas, o de tres meses si se producen por silencio.

La Mesa ha de resolver el recurso y notificar la resolución en el plazo de tres meses, transcurrido el cual se entiende desestimado. Las resoluciones se publican en la web, en los mismos términos establecidos en la Norma del Senado. Contra las resoluciones expresas o presuntas de la Mesa del Congreso cabe recurso contencioso-administrativo.

\section{c) Parlamentos autonómicos}

Como introducción a la normativa de las Cámaras autonómicas en materia de transparencia, puede tener interés la Declaración institucional adoptada por la Conferencia de Presidentes de Parlamentos autonómicos (COPREPA), reunida en Madrid el 31 de enero de 2015. De esta declaración destacamos dos apartados:

«Tercero: Que precisamente por su mayor proximidad, los Parlamentos Autonómicos deben ser modelo de transparencia y de buenas prácticas en la gestión, así como situarse en la vanguardia en la apertura de nuevos cauces de participación como la e-Democracia. Cuarto: Que los Presidentes de Parlamentos Autonómicos nos comprometemos a continuar con ese proceso de apertura a la ciudadanía, para que pueda conocer mejor el funcionamiento interno de las Cámaras, cuyo último ejemplo ha sido la apertura a la ciudadanía de la «Red Parlamenta», el sistema de intercambio de información parlamentaria de todas las Cámaras Autonómicas, al que también se puede acceder desde la página web de COPREPA. Asimismo, continuaremos con el fortalecimiento del uso de otras redes, como la red «REGPEX», que permite la defensa de nuestros intereses a nivel europeo».

Antes de la aprobación de la Ley estatal, algunas Asambleas se habían involucrado con intensidad en la tarea de la transparencia, como puede apreciarse en los resultados del Índice de 2013, en el que los dos primeros puestos son ocupados por los Parlamentos de Cantabria y Navarra, el primero con un 98,8 \%.

La disposición final novena de la Ley 19/2013 concede a los órganos de las Comunidades Autónomas y entidades locales un plazo máximo de dos años para adaptarse a las obligaciones contenidas en la Ley. Recuérdese que, también por respeto a la autonomía parlamentaria, la disposición adicional octava, al remitir a los Reglamentos la regulación de la aplicación concreta de las disposiciones de la Ley ${ }^{89}$, inclu-

89 Cuyo Título I les es de aplicación de conformidad con lo dispuesto en el art. 2.1.f «1. Las disposiciones de este título se aplicarán a: ...f) ...el Congreso de los Diputados, el Senado... y las instituciones autonómicas análogas, en relación con sus actividades sujetas a Derecho Administrativo». 
ye a las Asambleas Legislativas de las Comunidades Autónomas, junto al Congreso y al Senado.

1. Las leyes autonómicas aprobadas en materia de transparencia y acceso a la información pública ${ }^{90}$ contienen una norma similar de remisión a la normativa parlamentaria $^{91}$. Así, con formulaciones diversas, la Ley de Andalucía 1/2014, de 24 de Junio, de Transparencia pública de Andalucía (art. 3.2), la Ley 12/2014, de 16 de diciembre, de Transparencia y Participación ciudadana de la Comunidad Autónoma de la Región de Murcia (art. 5.2), la Ley de Canarias 12/2014, de 26 de diciembre, de transparencia y de acceso a la información pública (disp. adicional cuarta), la Ley 8/2015, de 25 de marzo, de Transparencia de la Actividad Pública y Participación ciudadana de Aragón (art. 4. 2) o la Ley 2/2015, de 2 de abril, de Transparencia, Buen Gobierno y Participación ciudadana de la Comunidad Valenciana (disp. adicional cuarta, que enumera las obligaciones que afectan a las Cortes y otros organismos). Excepción al respeto de la autonomía parlamentaria constituye la Ley 3/2014, de 11 de septiembre, de Transparencia y Buen Gobierno de la Rioja, cuyo art. 2 incluye en su ámbito de aplicación al Parlamento de La Rioja. Previamente, la Ley 4/2013, de 21 de mayo, de Gobierno Abierto de Extremadura, establecía normas de publicidad aplicables también a la Asamblea de Extremadura (disp. adicional tercera). En el extremo opuesto se sitúa la Ley 3/2015, de 4 de marzo, de Transparencia y Participación Ciudadana de Castilla y León, que no contiene referencia alguna a las Cortes de la Comunidad Autónoma.

Más detallada es la Ley de Cataluña 19/2014, de 29 de diciembre, de transparencia, acceso a la información pública y buen gobierno, cuya disposición adicional quinta, tras un primer apartado de reconocimiento de la autonomía parlamentaria, establece un amplio listado de tareas a realizar por el Parlamento, con la peculiaridad de que el apartado 3 impone que estas adaptaciones normativas habrán de llevarse a cabo antes de la entrada en vigor de la ley — mandato que sólo entra en vigor con la propia Ley, esto es, a los seis meses de su publicación. No obstante, la reforma parcial del Reglamento del Parlamento de Cataluña se aprobó el 8 de julio de 2015. Una buena técnica legislativa ayudaría a evitar incoherencias de este tipo.

90 Sobre el porqué de una ley autonómica propia sobre transparencia, puede verse FERNANDEZ RAmos, S. y Pérez Monguió, J.M., Transparencia, acceso a la información pública y buen gobierno. Ley 19/2013, de 9 de diciembre, Aranzadi, Madrid, 2014, p. 66 y ss.

91 En un sentido más amplio, la disposición adicional cuarta de la Ley Foral de Navarra 11/2012, de 21 de junio, de la transparencia y del gobierno abierto, establece: «Las distintas instituciones de la Comunidad Foral de Navarra adoptarán en su propio ámbito de competencias, en el plazo de un año, medidas de transparencia y participación y colaboración ciudadanas conforme e los principios y previsiones contenidos en la presente Ley Foral». 
Con anterioridad a la Ley 19/2013, el art. 108 del Reglamento del Parlamento Vasco, reformado el 30 de junio de 2011 (BOPV 8 julio 2011), establece la transparencia como principio y reconoce a todo ciudadano el derecho a acceder a los documentos parlamentarios.

2. En materia de publicidad activa, algunos Reglamentos imponen la publicación en la página web de determinados documentos (los cuales, sin modificación reglamentaria, también se publican en otras páginas web parlamentarias). Regula el contenido del portal de transparencia el nuevo art. 66 bis del Reglamento del Parlamento de Andalucía. El Reglamento impone asimismo la publicación de las asistencias de los diputados a las sesiones (art. 13.3), el Registro de Actividades, bienes e intereses (art. 16.3) (22 $^{2}$, las autoliquidaciones tributarias anuales de los impuestos sobre la renta y el patrimonio, salvo los extremos que la Mesa considere afectan al derecho a la intimidad (art. 16.4; voluntariamente, también las declaraciones del cónyuge, con su consentimiento). Asimismo, se publicará la contabilidad de las subvenciones parlamentarias recibidas por los grupos parlamentarios y las cantidades que estos abonen a cada diputado (art. 25.3 y 4).

De forma similar, en Extremadura, el art. 18 del Reglamento de la Asamblea $^{93}$ prevé la publicación en la página web de la declaración de la renta y, en su caso, patrimonio, presentada para adquirir la condición de diputado, excluyendo determinados datos que afectan a la intimidad, así como las de los años sucesivos. Se publicarán asimismo los conceptos retributivos de los diputados, el acuerdo de la Mesa que fije la cuantía del importe de las dietas y el kilometraje que perciben los diputados (art. 20), las declaraciones de actividades, bienes, derechos e intereses de éstos (art. 32) ${ }^{94}$. Una amplia enumeración de información mínima a incluir en el portal de transparencia contiene el nuevo art. 110 ter del Reglamento de las Cortes Valencianas, incluyendo el acceso a la agenda de los diputados. Tal vez este detallismo

92 También en el Reglamento de los Parlamentos de Canarias, art. 18.3, Galicia, art. 12 y Cataluña, art. 19.6. Se publican asimismo en otras páginas web parlamentarias, como en el Congreso y en el Senado desde 2009 (actividades) y 2011 (bienes), según se ha indicado supra, y en el Parlamento de las Islas Baleares (nuevo art. 21.2 bis). En otros casos, se establece la publicación en el Boletín Oficial del Parlamento, véase por ejemplo la Resolución de carácter general 3/VII, de 2 de febrero de 2010, de la Mesa de las Cortes Valencianas (BOC n. ${ }^{\circ}$ 206, 3 febrero 2010).

93 Nueva numeración conforme a la Reforma de 19 de marzo de 2015 (DOE n. ${ }^{\circ} 70,14$ abril 2015).

94 De otra parte, conforme al art. 119.7, se publicarán en la página web de la Asamblea las actividades de régimen interior y funcionamiento tanto de sus órganos de gobierno como de los grupos parlamentarios. Se entenderá por régimen interior su presupuesto anual, los medios materiales y humanos adscritos, provisión, régimen retributivo nominal, deber de transparencia que se extiende a los organismos o entidades adscritas o dependientes de la Asamblea de Extremadura. El principio de transparencia aparece el primero de los que, conforme al art. 120, rigen el funcionamiento del Parlamento: transparencia, agilidad, inmediatez, publicidad e igualdad de derechos. Conforme a este art., en el ejercicio de sus funciones parlamentarias, los diputados y los miembros del Gobierno actuarán bajo el principio de la buena fe. En otro orden de cosas, el art. 124.4 establece que el presidente del Parlamento, de acuerdo con la Mesa de la Cámara, determinará la forma en que las comisiones serán retransmitidas por Internet o por cualquier otro medio audiovisual. 
sea excesivo para una norma tan rígida como el Reglamento, y más propio de un acuerdo de la Mesa, al que se remite, por ejemplo, el nuevo art. 213 del Reglamento del Parlamento de Canarias. Véanse también los arts. 204 y ss. del Texto Refundido del Reglamento del Parlamento de Cataluña. También en materia de publicidad activa, el Acuerdo de la Mesa de las Cortes de Castilla-La Mancha de 10 de febrero de 2014, por el que se amplía y refuerza la transparencia de la actividad parlamentaria ${ }^{95}$, amplía los contenidos de la página web de las Cortes, en cuanto a información institucional, de relevancia jurídica y económica, presupuestaria y estadística.

Es significativo que comience a introducirse en los Reglamentos el cumplimiento de las obligaciones derivadas del principio de transparencia como deber de los diputados, así en el art. 16.3 del Reglamento del Parlamento de Canarias. En esta Comunidad, la novedosa figura del comisionado de Transparencia y Acceso a la Información Pública, presentará un informe anual al Parlamento sobre el cumplimiento de la Ley 12/2014, de 26 de diciembre, de transparencia y de acceso a la información pública, que en su caso será debatido en Pleno o en Comisión, si la Mesa así lo acuerda.

3. Sin perjuicio de las modificaciones reglamentarias, las Mesas de las Cámaras autonómicas han dictado normas en materia de acceso a la información pública. Así, las Normas relativas al derecho de acceso a la información en el Parlamento de Andalucía, derecho reconocido a «toda persona física o jurídica que resida o tenga su domicilio social en Andalucía, tenga o no un interés legítimo que justifique el acceso, así como cualquier medio de comunicación social, esté o no acreditado en la Cámara» (art. 2) ${ }^{96}$.

Resuelve las solicitudes la Secretaría General en el plazo máximo de veinte días hábiles, prorrogables por igual periodo, sin perjuicio de que el Gabinete de Prensa pueda facilitar a los medios de comunicación social la información sobre las actividades de los órganos del Parlamento.

En el Parlamento de Cantabria, en el documento publicado en su web «Prácticas y actuaciones seguidas en el Parlamento de Cantabria sobre transparencia parlamentaria que todos los parlamentarios conocen y cumplen», además de proclamar el compromiso de transparencia y la publicación de la información con sujeción a los límites y principios de la Ley 19/2013, se reconoce a todas las personas el derecho a acceder a la información pública que obre en poder del Parlamento de Cantabria y que haya sido elaborada o adquirida en el ejercicio de sus funciones, siendo el órgano administrativo responsable de la tramitación de las solicitudes de información el Servicio de Protocolo y Relaciones Institucionales y correspondiendo la

95 BOCCLM n. ${ }^{\circ} 133$, de 11 de febrero de 2014.

96 La limitación subrayada no aparece en la Ley de Andalucía 1/2014, de Transparencia pública de Andalucía, la cual se remite en su art. 24 al derecho de todas las personas a la información veraz reconocido en la Constitución y el Estatuto de Autonomía. 
competencia para resolver a la Mesa de la Cámara. Su decisión, en las actividades del Parlamento sujetas a Derecho Administrativo, estará sometida al régimen de recurso que determina la Ley de la jurisdicción contencioso-administrativa.

Véanse también los arts. 209 y ss. del Texto Refundido del Reglamento del Parlamento de Cataluña, tras la reforma parcial de 8 de julio de 2015 y el Acuerdo de la Mesa de la Asamblea de Madrid de 20 de mayo de 2015.

\section{PARLAMENTO Y PARTICIPACIÓN CIUDADANA}

\section{Acercamiento a la ciudadanía. Parlamento abierto}

Constituye una preocupación creciente de nuestros Parlamentos (y de las instituciones públicas en general) el acercarse a los ciudadanos y conseguir establecer una relación bidireccional con ellos ${ }^{97}$. A ellos tienden los contenidos de las páginas web (apartados de relaciones con los ciudadanos o participación), además de los canales parlamentarios de difusión de la actividad, la multiplicación de las jornadas de puertas abiertas o las visitas a las Cámaras, así como la más reciente utilización de las redes sociales.

En nuestra referencia a la renovación de la función legislativa se ha podido observar cómo las iniciativas más innovadoras de participación ciudadana en nuestro país se han implantado en los Parlamentos autonómicos.

Sin perjuicio de la iniciativa popular reconocida constitucional y estatutariamente $^{98}$ y del derecho de petición ${ }^{99}$, y con independencia de las distintas leyes

97 Participación es una voz mágica, dice Tudela Aranda, J. («Participación en el procedimiento de elaboración de la ley», cit., p. 95), en muchas ocasiones la sensación es que todos los males del mundo desaparecerían si se participase.

98 También en los Reglamentos parlamentarios pueden introducirse modificaciones que faciliten y potencien la tramitación de la iniciativa popular más allá de su inclusión en el orden del día en el plazo de seis meses y la posible defensa de la proposición por uno de sus promotores (con remisión a los Reglamentos de las Cámaras), previstas en la LO 4/2006, de 26 de marzo, que modifica la LO 3/1984, de 26 de marzo, reguladora de la iniciativa legislativa popular, para facilitar la participación y agilizar la tramitación. Véase en este sentido la Ley catalana 7/2014, de 25 de junio, de modificación de la Ley 1/2006, de 16 de febrero, de la iniciativa legislativa popular, que reduce el plazo a cuatro meses para el debate de totalidad y amplía la intervención en el debate del representante de la Comisión promotora y su participación en la tramitación posterior de la iniciativa (véanse los arts. 136 a 139 del Reglamento del Parlamento). El art. 125 del Reglamento del Parlamento de Andalucía establece un plazo máximo de dos meses desde la verificación por la Mesa del cumplimiento de los requisitos legales y faculta al representante de la comisión promotora para estar presente en las comparecencias informativas y asistir a las sesiones de la comisión y del Pleno, pudiendo intervenir en dichas sesiones antes que los representantes de los grupos parlamentarios. El Reglamento del Parlamento de Canarias (art. 140) introduce asimismo la presentación por un representante de la comisión promotora en el debate de la toma en consideración. El Reglamento de las Cortes Valencianas (art. 126.3) le concede el derecho a la presentación, antes de su toma en consideración, en la comisión correspondiente.

99 En algunos Parlamentos autonómicos, la tradicional Comisión de Peticiones ha cambiado su denominación: Comisión de Peticiones y Defensa del Ciudadano, en La Rioja; Comisión de Comparecencias y Peticiones ciudadanas, en las Cortes de Aragón. Sobre la posible renovación del derecho de petición y un 
autonómicas en materia de participación ciudadana y gobierno abierto — referidas al Ejecutivo_- , se han incluido ya en los Reglamentos parlamentarios algunas medidas de participación de la ciudadanía. Destacan las adoptadas por el Parlamento de Andalucía en la reforma de su Reglamento de 26 de noviembre de 2014 (BOJA n. ${ }^{\circ}$ 241, 11 diciembre 2014), si bien con anterioridad se habían regulado ya las comparecencias en Comisión de agentes sociales y organizaciones interesadas y la formulación de preguntas de iniciativa ciudadana. Pionero fue también el Parlamento Vasco, en la reforma del Reglamento de 30 de junio de 2011 (BOPV 8 julio 2011), destacando el art. 109 ${ }^{100}$, que establece una serie de medidas para facilitar el contacto entre la ciudadanía y los parlamentarios.

Mención especial merece la Reforma del Reglamento de las Cortes Valencianas de 25 de marzo de 2015 (BOCV n. ${ }^{\circ} 328,8$ abril 2015), que incorpora un nuevo Título denominado «Del parlamento abierto». Se crea una Comisión no legislativa Especial de participación ciudadana, ante la que podrán comparecer, antes del plazo de enmiendas a los proyectos de ley, los representantes de colectivos sociales y organizaciones acreditadas, además de profesionales y expertos y representantes de corporaciones de derecho público, así como de los alcaldes de los municipios de la Comunidad Valenciana, para dar traslado de los asuntos que afecten a sus consistorios y sean competencia de la Generalitat $^{101}$. Asimismo, se añade al Reglamento un capítulo sobre la participación directa de los ciudadanos a través de las tecnologías de la información y de la comunicación, que prevé el establecimiento de un procedimiento telemático para que los ciudadanos puedan participar directamente y hacer llegar a los grupos sus observaciones y sugerencias sobre las iniciativas legislativas y proposiciones no de ley en tramitación, otras aportaciones y sugerencias que deban

eventual protagonismo del mismo en sede parlamentaria — «un desafío a la imaginación»—, puede verse Tudela Aranda, J., «Parlamento y política legislativa en materia de participación ciudadana», Deliberación, n. ${ }^{\circ} 1,2010$, p. 81 y ss.

100 Este artículo entre otras medidas, fija un plazo de dos o tres días para que estén disponibles los documentos escritos o gráficos y sonoros, respectivamente, y establece el derecho de información al menos semanal a los interesados sobre la tramitación de iniciativas que hayan elegido, la retransmisión en directo de las sesiones plenarias a través de internet y un sistema de avisos que permita a los ciudadanos interesados en iniciativas concretas recibir información por canales electrónicos sobre la fecha y órgano que la tramitará. El aviso permitirá acceder al expediente completo de la iniciativa.

101 Las sesiones de la Comisión, formada por un representante de cada grupo parlamentario, serán presididas por la Mesa de las Cortes, públicas y de carácter informativo, y sus conclusiones no serán vinculantes. «Pese a que esta comisión es de carácter informativo y no deliberante, en el caso de tener que adoptar alguna decisión", lo hará por voto ponderado. Las peticiones de comparecencia se formulan por los interesados ante la Mesa de la Comisión una vez tramitado un proyecto de ley, en el plazo de cinco días, decidiendo aquella sobre la oportunidad de la comparecencia y excepcionalmente, sobre la posibilidad de exposición por escrito, que se hará llegar a los grupos parlamentarios. Cada grupo parlamentario podrá elegir una de las comparecencias no incorporadas por la Mesa para que se incluyan en el orden del día y se proceda a su sustanciación. Las comparecencias deberán concluir en el plazo máximo de quince días hábiles, transcurrido el cual la Mesa abrirá el plazo de enmiendas. No obstante, se se excluyen de este procedimiento distintas materias, además de los decretos legislativos y los decretos leyes, así como las proposiciones de iniciativa legislativa popular. 
ser contestadas, y enmiendas a los textos legislativos, que debe asumir un grupo parlamentario para ser tramitadas ${ }^{102}$.

También la reforma del Reglamento del Parlamento de Cataluña de 8 de julio de 2015 incorpora un capítulo «Parlamento abierto» (arts. 222-226 del Texto Refundido), con instrumentos participativos como las audiencias, espacios de participación y colaboración en la tramitación de las iniciativas legislativas, diálogo con los ciudadanos y evaluación de estos procesos.

\section{Medidas de participación ciudadana}

Algunas de las medidas concretas de participación ciudadana incluidas en la normativa parlamentaria son las siguientes:

Con el carácter de foro de participación en cuestiones de actualidad e interés general, en el seno de la Asamblea de Extremadura (art. 271 del Reglamento) se constituye el Consejo Extremeño de Ciudadanos y Ciudadanas, como foro de consulta para la participación ciudadana, conforme a lo dispuesto en el art. 38 de la Ley de Gobierno Abierto de Extremadura. Su desarrollo reglamentario corresponde a la Mesa de la Cámara ${ }^{103}$.

Realización en general de sugerencias y aportaciones por vía electrónica, con derecho a conocer el resultado de las mismas (Parlamento Vasco, art. 110 RPV ${ }^{104}$, derecho a contestación en las Cortes Valencianas, art. 110 bis 4 RCV). Buzones de sugerencias existen también en las páginas web del Senado y de distintos Parlamentos autonómicos.

Audiencia de organizaciones de intereses en el procedimiento legislativo. Así, en Andalucía (art. 112), Extremadura (art. 164) y Cataluña (art. 115), a propuesta de los grupos parlamentarios una vez celebrado el debate de totalidad. La Mesa (Andalucía) o la comisión (Cataluña) acuerdan las comparecencias a cele-

102 Tal vez las novedades más relevantes de esta reforma respecto a otras normas autonómicas sean el mandato a las Cortes de que concluyan convenios de colaboración con entidades que promuevan la democracia participativa por medio de las tecnologías de la información y comunicación (art. 110 bis.3) y de que faciliten el trabajo de las organizaciones cívicas de monitorización parlamentaria e impulsen convenios de colaboración con el objeto de mejorar el funcionamiento y transparencia de la Cámara (art. 110 ter.7).

103 El Consejo Extremeño de Ciudadanos estará formado por todos los colectivos y ciudadanos que deseen formar parte del mismo y participen en sus reuniones, las cuales podrán celebrarse en las distintas localidades de la comunidad. A tal efecto, se creará el Registro de Participación y Colaboración Ciudadanas, donde deberán inscribirse los ciudadanos y entidades ciudadanas que voluntariamente quieran participar en dicho foro. Anualmente, el Consejo elevará a la Mesa de la Asamblea, para que lo dé a conocer públicamente y sea debatido en Pleno, un informe acerca del grado de satisfacción de la ciudadanía con el efectivo cumplimiento de los principios de participación ciudadana por parte de las instituciones, estableciendo propuestas o sugerencias de mejora en dicho campo.

104 Reglamento del Parlamento Vasco. «Art. 110. El espacio sobre participación del sitio web del Parlamento Vasco estará igualmente disponible para que cualquier ciudadano o ciudadana pueda efectuar sus sugerencias y aportaciones públicamente y conocer el resultado de las mismas». 
brar. En Andalucía y Extremadura, el Reglamento establece que quienes comparezcan habrán de tener la consideración de representantes de colectivos sociales, sean éstos públicos o privados, afectados por el contenido del proyecto de ley. Sólo con carácter excepcional podrán ser llamadas a comparecer personas a título individual $^{105}$. Una regulación similar se ha introducido en el Reglamento de las Cortes Valencianas (arts. 182 ter y quater) en su reciente reforma. Véase asimismo en el art. 189.1.2. ${ }^{\circ}$ del Reglamento del Parlamento de Canarias la previsión general de comparecencia de personas pertenecientes a entidades, organizaciones y grupos sociales representativos en las materias propias del conocimiento de una comisión.

En las Cortes de Aragón, las solicitudes de comparecencia de representantes de colectivos sociales, personas físicas o representantes de personas jurídicas se prevén con carácter general en el art. 56 del Reglamento, desarrollado por Resolución de la Presidencia de 29 de septiembre de 2000. La Mesa de las Cortes califica las solicitudes, quien las trasladará a la Comisión de Comparecencias y Peticiones Ciudadanas (antes, de Peticiones y Derechos Humanos), salvo que por circunstancias del trabajo parlamentario se considere pertinente remitirlas a otra Comisión permanente. Las Mesas de las Comisiones permanentes pueden solicitar a la Mesa de las Cortes, cuando existan razones que lo justifiquen, que alguna de estas comparecencias se celebre ante otra Comisión. Una vez calificadas, la convocatoria e inclusión en el orden del día se realizará a criterio de la Mesa de la Comisión, quien podrá incluso rechazar su celebración, si no la considerara oportuna ${ }^{106}$.

En todas estas normas, apreciamos cómo, en suma, la decisión sobre la comparecencia se deja en manos de la mayoría, lo que podría llegar a privar de eficacia al nuevo instrumento de participación ${ }^{107}$, por más que sea la regla en la dinámica parlamentaria.

Aportaciones a los procesos legislativos por vía de sugerencias o de debate en foros: Parlamento Vasco (ADI: aporta, debate, influye), Corts valencianas (nuevo art. 110 bis). Sin regulación reglamentaria, existen también estos foros o consultas sobre las iniciativas en tramitación en las páginas web de los Parlamentos de Cataluña (Escó 136), Galicia (Lexisla con Nós), Andalucía, Cantabria, Navarra, Cortes de Aragón, Asamblea Regional de Murcia y Asamblea de Extremadura.

105 Tudela Aranda, J., «Participación en el procedimiento de elaboración de la ley», cit., p. 106, considera que los diputados deben estar legitimados para realizar la solicitud de comparecencias, pero que no deben abrirse a sujetos individuales, más apropiados para comparecer como expertos en una comisión de estudio.

106 La Resolución establece que estas comparecencias tienen carácter meramente informativo, por lo que su sustanciación se limitará a una intervención de 30 minutos, en la que se expondrán a la Comisión las razones de la comparecencia, salvo que excepcionalmente la Mesa de la Comisión acuerde otra ordenación distinta, oídos los representantes de los Grupos parlamentarios.

107 No tiene sentido, dice Tudela Aranda, J., «Participación en el procedimiento de elaboración de la ley», cit., p. 107: apostar por la participación y realizarlo en los términos descritos es radicalmente contradictorio. Es difícil postular la participación cuando ésta se niega a los grupos de la oposición. 
Un paso más supone reconocer a asociaciones representativas de intereses la posibilidad de presentar enmiendas al articulado a las iniciativas legislativas, como las denominan los Reglamentos del Parlamento de Andalucía (art. 114 bis) y de las Cortes Valencianas (art. 113 bis), si bien para que puedan tramitarse como tales deberán ser asumidas por algún Grupo Parlamentario mediante escrito presentado en el plazo para registrar las enmiendas. No obstante, en la tramitación se hará constar la autoría de estas y el Grupo que las asuma no podrá modificar su contenido (sin consentimiento del proponente, en las Corts).

En definitiva, sería la articulación de un mecanismo institucionalizado de lobby, que viene ya utilizando en nuestras Cámaras la vía informal del envío de enmiendas a los grupos parlamentarios ${ }^{108}$.

En materia de control e información, los Reglamentos de los Parlamentos de Andalucía (art. 165) y Canarias (art. 177) han introducido las preguntas de iniciativa ciudadana, que debe asumir un diputado para su tramitación ante el Pleno o en Comisión ${ }^{109}$; en su intervención hará constar el autor de la iniciativa (salvo que éste haya solicitado expresamente permanecer en el anonimato, en Canarias) y no podrá modificar de forma sustancial el contenido originario del texto de la pregunta. En cada sesión plenaria se formulará un número máximo de preguntas de este tipo (cuatro en Andalucía, dos en Canarias), incluyéndose en el orden del día por orden cronológico de presentación (salvo razones de urgencia o de actualidad, Canarias), cuando la materia sobre la que verse la pregunta así lo aconseje. En Andalucía, se especifica que su inclusión consume cupo.

De orden más documental y de transparencia, ha de citarse la posibilidad de suscribirse para recibir telemáticamente información periódica sobre temas de interés o avisos sobre iniciativas concretas: Zabalik, servicio semanal de difusión de la actividad parlamentaria (art. 109.c y f Reglamento del Parlamento Vasco) ${ }^{110}$.

108 Por cuestiones de lenguaje, como señala Tudela Aranda, J., «Participación en el procedimiento de elaboración de la ley», cit., p. 110, si se habla de lobby, de grupos de presión, se frunce el ceño, se levanta la barrera y se niega la evidencia. Si, por el contrario, se habla de participación, se esboza la sonrisa, se levantan las compuertas y se saluda con afecto. En este sentido, el nuevo art. 224 del Reglamento del Parlamento de Cataluña prevé la posibilidad de presentar sugerencias o propuestas de modificación a los proyectos y proposiciones de ley en los espacios de participación y colaboración ciudadana que establezca la Mesa. En las memorias sobre el impacto de los procesos participativos en las iniciativas legislativas, deberá reflejarse la influencia de aquel en la ley anulada (art. 226,5).

109 Si son varios los diputados que desean asumir una misma pregunta, se le asignará al primero que manifieste (fehacientemente, en Canarias) su intención de hacerlo. En Canarias, las preguntas admitidas a trámite y no asumidas por un diputado en quince días desde su admisión se considerarán decaídas. La decisión sobre si la pregunta se tramita en Pleno o en Comisión corresponde al diputado que la haya asumido, y si no hace ninguna indicación, en Canarias corresponde su tramitación ante el Pleno. Finalizado un periodo de sesiones, las preguntas asumidas y no sustanciadas en Pleno o en Comisión en Canarias se tramitarán como preguntas con respuesta por escrito, aplicándose en Andalucía el régimen general de caducidad anual tras el primer periodo de sesiones.

110 Servicios similares ofrecen otras páginas web de Parlamentos: en Galicia y Aragón, suscripciones a áreas temáticas; en Asturias, información puntual o periódica; en La Rioja, suscripción gratuita a Boletines, 
El texto refundido del Reglamento del Parlamento de Cataluña contiene un capítulo sobre la relación del Parlamento con corporaciones, entidades y asociaciones (arts. 196-198), en el que se prevé la posibilidad de comparenencia de entidades y grupos sociales en plenos monográficos o extraordinarios relacionados con su objeto a petición de dos grupos parlamentarios y por acuerdo de la Junta de Portavoces, así como la invitación de personalidades relevantes a comparecer ante el Pleno, también por decisión del Presidente del Parlamento.

Finalmente, el acercamiento a la sociedad se persigue también por otros medios, que vienen desarrollándose desde hace tiempo en todos los parlamentos: visitas al edificio sede del Parlamento, asistencia a las sesiones plenarias, actividades para escolares... En las Cortes Valencianas, pese a la ausencia de previsión reglamentaria, se prevé desde la Resolución de carácter general 1/VII la posibilidad de asistencia de público a las sesiones de las comisiones. Esta resolución ha sido sustituida por otra de 17 de abril de 2012 (BOC n. ${ }^{\circ} 68$, de 20 de abril), con un contenido similar: sin perjuicio de la presencia de los representantes de los medios de comunicación en la tribuna de prensa y de la prioridad de las peticiones de los altos cargos de la Administración, la presidencia de la comisión puede autorizar, atendiendo a la limitación de espacio de la sala, la asistencia de público a una sesión, habilitando hasta un máximo de cinco asientos, que se situarán delante de la tribuna de prensa. Se aplican las normas de disciplina parlamentaria previstas en el Reglamento para el Pleno de la Cámara.

Debe perseverarse en estas vías dirigidas a buscar medios de acercamiento de y a la ciudadanía (a la ciudadanía en general, no sólo a las llamadas por Sartori minorías intensas, que tienden a utilizar casi en exclusiva los cauces de participación), y a fortalecer el conocimiento de la institución parlamentaria y el papel de los representantes.

\section{OTRAS MEDIDAS DIRIGIDAS A LA RECUPERACIÓN DE LA CONFIANZA EN EL PARLAMENTO}

Además de las medidas encaminadas al acercamiento a la sociedad y la participación ciudadana, nuevas iniciativas de mayor transcendencia, pues requieren de modificaciones legislativas de envergadura, o incluso estatutarias, han surgido de la conjunción de dos causas: la crisis económica y su repercusión en la sociedad - que ha generado una visión más crítica de las instituciones-, de una parte, y el deseo de superar el descrédito de las instituciones parlamentarias y recuperar la confianza del electorado.

Diarios de sesiones o leyes aprobadas, pudiendo señalar el contenido requerido; en Extremadura, información periódica sobre actividad parlamentaria o institucional; también en Madrid y Castilla y León. 


\section{Reducción de número y retribuciones de los parlamentarios}

Podemos situar aquí las iniciativas dirigidas a la ampliación de los periodos ordinarios de sesiones ${ }^{111}$ y a la reducción del número de los diputados en determinadas Asambleas autonómicas, así como a la modificación de sus retribuciones. Las dos últimas medidas se situarían en la línea de un retorno a los Pactos de La Moncloa de 1981, que se plasmaron en los Estatutos de Autonomía aprobados con posterioridad.

En cuanto a la reducción del número de diputados, parece ampliamente justificada en supuestos como el de la Asamblea de Madrid, para la que el Estatuto reformado por Ley Orgánica 5/1998 prevé que esté compuesta por un diputado por cada 50.000 habitantes o fracción superior a 25.000, de acuerdo con los datos actualizados del censo de población, lo que ha elevado de forma automática su número, llegando a extremos excesivos (129 en las convocatorias de elecciones de 2011 y 2015) si se comparan con el número de diputados al Congreso, y además incomprensibles para la ciudadanía, que muchas veces contempla a las instituciones en términos de gasto público ${ }^{112}$.

La Ley Orgánica 2/2014, de 21 de mayo, de reforma del Estatuto de Castilla-La Mancha, reduce el número de diputados de las Cortes de esta Comunidad Autónoma a un mínimo de 25 y un máximo de 35, siendo 49 los miembros existentes en el momento de su aprobación ${ }^{113}$. La STC 197/2014, de 4 de diciem-

111 El art. 79 del Reglamento de las Cortes de Castilla-La Mancha, redactado conforme a la reforma de 4 de diciembre de 2014, establece como periodos ordinarios de sesiones de septiembre a diciembre y de enero a julio, eliminando, por tanto, los meses de enero y julio de las mal llamadas «vacaciones parlamentarias» que respecto al Congreso de los Diputado y al Senado fija el art. 73.1 de la Constitución.

112 Como recuerda Navarro, J.I., «Algunas propuestas para la mejora del rendimiento institucional de las Asambleas Legislativas autonómicas españolas», cit., p. 72 y ss., en la actualidad hay en nuestro país 1268 diputados autonómicos. Añade: «si no cabe duda de que los tiempos en que vivimos exigen respuestas ejemplares y decididas tendentes a equilibrar los ingresos y los gastos públicos, sin embargo no estamos muy seguros de que una de ellas tenga que ser, necesariamente, el redimensionamiento a la baja de nuestras asambleas legislativas regionales, en una carrera desenfrenada por ver quién es capaz de recortar más»; habrán de tenerse en cuenta elementos como la relación entre el número de diputados y la población de la Comunidad Autónoma o el coste efectivo de funcionamiento de la Cámara antes de tomar una decisión. «El principal riesgo de 'sacar la tijera' y aceptar este tipo de propuestas que, sin duda gozan de una enorme popularidad entre la ciudadanía, es que pueden hacer de nuestros Parlamentos unas instituciones más baratas, pero también menos representativas y de menor calidad en los resultados que producen. Por ello, se ha criticado, creemos que con razón, que estas medidas reductivas fomentarían o consolidarían el bipartidismo ya predominante y, por ende, producirían Cámaras legislativas menos plurales, al limitar el acceso a las mismas a los partidos minoritarios».

113 La redacción anterior (LO 3/1997) establecía una distribución mínima de escaños: Albacete, 10; Ciudad Real, 11; Cuenca, 8; Guadalajara, 7; Toledo, 11. La redacción originaria del Estatuto fijaba un arco de 47 a 59 diputados. Una crítica a la reducción de parlamentarios en las Cortes de Castilla-La Mancha en ArANDa Alvarez, E., «Reformas electorales en las Comunidades Autónomas: ¿reducción del déficit o ventaja electoral?», Comunicación presentada al XIII Congreso de la Asociación de Constitucionalistas de España celebrado en Zaragoza en febrero de 2015. Véase también del mismo autor «La reducción de parlamentarios y la modificación del régímen retributivo de los miembros de las Asambleas de las Comunidades Autónomas», Revista de Derecho Político n. ${ }^{\circ}$ 92, 2015, pp. 119-164, que concluye con una propuesta para repensar los Parlamentos autonómicos. 
bre, desestima un recurso de inconstitucionalidad contra esta reforma estatutaria, sobre la base de que el Tribunal no juzga «las hipotéticas o presuntas intenciones' con las que disposiciones o actos jurídicos hayan sido adoptados, sino la constitucionalidad o inconstitucionalidad de las determinaciones del poder público» que puedan ser sometidas a su examen (FJ1). El Tribunal reconoce que la reducción de la magnitud de las circunscripciones no favorece, «más bien al contrario», la mayor proporcionalidad del sistema electoral de que se trate, pero considera que «la exigencia constitucional sobre el legislador en orden a configurar para la elección de las asambleas legislativas autonómicas un sistema de representación proporcional viene a cifrarse, ante todo, en mandatos de alcance negativo». No cabe imputar una «abolición de la proporcionalidad» por la aminoración de la composición de las Cortes y la consiguiente reducción de la magnitud de las circunscripciones. La norma estatutaria sigue exigiendo un sistema de representación proporcional «y el grado, incierto hoy, en el que la proporcionalidad pueda llegar a contraerse a resultas de lo dispuesto en la Ley Orgánica o de la legislación que la desarrolle», no es algo que pueda ser enjuiciado en ese proceso constitucional. No vulnerada la proporcionalidad que exige el art. 152.1 CE, «tampoco lo han sido ni el pluralismo político ni la norma que enuncia el derecho de acceso a los cargos públicos en condiciones de igualdad y de conformidad con los requisitos que señalen las leyes (arts. 1.1 y 23.2 CE)» (FJ7).

Por los mismos argumentos, la STC 15/2015, de 5 de febrero, desestima el recurso de inconstitucionalidad contra la Ley 4/2014, de 21 de julio, de reforma de la Ley 5/1986, de 23 de diciembre, electoral de Castilla-La Mancha, que adapta el sistema electoral autonómico a la modificación del Estatuto de Autonomía. El Tribunal constata «que la específica disminución del número de escaños a elegir en cada una de las circunscripciones que de tal reducción se sigue en modo alguno impide toda posible proporcionalidad —en el grado y extensión que sea- del sistema electoral para la integración de las Cortes de la Comunidad Autónoma» ${ }^{114}$.

En cuanto a la modificación reglamentaria del sistema de retribuciones de los diputados, implantada y contestada en Castilla-La Mancha ${ }^{115}$, la duda sobre su constitucionalidad ha sido resuelta por la STC 36/2014, de 27 de febrero ${ }^{116}$ (que deses-

114 Si la magnitud de las circunscripciones «no imposibilita, en sí misma, tal posible despliegue de la proporcionalidad no podrá ya censurarse la opción legislativa en términos jurídico-constitucionales, so pena de convertir la legítima crítica política en argumento de inconstitucionalidad; en ello incurre a menudo la demanda al calificar, por ejemplo, de 'poco creíble y poco fiable' esta reforma de la Ley electoral» (FJ8).

115 Distinguiendo, conforme al nuevo art. 11 del Reglamento de las Cortes, entre los diputados en régimen de dedicación exclusiva e incompatibilidad, únicos que percibirían un sueldo, y el resto, que recibirán asistencias por la concurrencia efectiva a las sesiones de los órganos de que formen parte, en la cuantía que señale la Mesa oída la Junta de Portavoces. Además, todos los diputados percibirán una cantidad en concepto de indemnización por los gastos derivados de sus funciones representativas. Todas las asignaciones estarán sujetas a las normas tributarias de carácter general y se incluirán en la declaración de bienes de los diputados.

116 Una crítica de esta sentencia en GARcía RocA, J., «La supresión — sobrevenida— del sueldo de los diputados de Castilla-La Mancha según la STC 36/2014, de 27 de febrero: una solución sencilla para un problema complejo", Cuadernos Manuel Giménez Abad, n. ${ }^{\circ}$ 7, 2014, p. 93 y ss., quien se plantea como cuestión central: 
tima el recurso de inconstitucionalidad presentado por 60 senadores del Grupo Socialista), en la que el Tribunal se reitera en su doctrina de que sólo poseen relevancia constitucional los derechos y facultades atribuidas al representante que pertenezcan al núcleo de su función representativa parlamentaria. La Constitución no configura el régimen retributivo de los miembros de las Asambleas Legislativas de las Comunidades Autónomas, habrá que estar por tanto a lo que determinan los Estatutos de Autonomía. En el caso de Castilla-La Mancha, la reforma operada por Ley Orgánica 3/1997, de 3 de julio, eliminó toda referencia a las retribuciones o asignaciones de los diputados de las Cortes regionales, y «en consecuencia, y partiendo del nuevo marco estatutario, las Cortes de Castilla-La Mancha, en el libre y legítimo ejercicio de su autonomía reglamentaria, aprobaron la reforma de los arts. 11 y 12 del Reglamento de la Cámara», implantando el nuevo sistema, «sin que existan razones para considerar inconstitucional dicha reforma, pues no ha quedado acreditado que el nuevo régimen retributivo origine perjuicios económicos en el desarrollo del núcleo esencial de la función representativa ${ }^{117}{ }_{\text {» }}(\mathrm{FJ} 8)$.

Cuestionada la aplicación de la reforma con carácter retroactivo, tampoco considera el Tribunal Constitucional que la implantación del nuevo régimen en el curso de la legislatura haya supuesto una restricción de derechos individuales en el sentido prohibido por el art. 9.3 $\mathrm{CE}^{118}$.

Sean las expuestas u otras las medidas adoptadas en el ámbito de la autonomía parlamentaria, deben siempre tenerse presentes dos aspectos implicados:

— que la eliminación, no ya de privilegios parlamentarios en el sentido técnico del término, sino de «beneficios» derivados de la función, en un marco de austeridad ${ }^{119}$, será siempre bien recibida por la ciudadanía;

¿devaluará la medida el ejercicio de la función de control del ya todopoderoso ejecutivo autonómico al dejarla en manos de unos parlamentarios aficionados o poco profesionalizados y con escaso tiempo de dedicación? (p. 97).

117 «Por tanto, no puede afirmarse, como pretenden los recurrentes, que una determinada modalidad retributiva como es la percepción de un sueldo fijo constituya, per se, un derecho que forma parte del núcleo esencial del derecho fundamental a acceder en condiciones de igualdad a las funciones y cargos públicos protegido por el art. 23.2 CE, y, por consiguiente, un derecho que no pueda ser objeto de reforma reglamentaria cuando la Cámara, en virtud del principio de autonomía, así lo decida, y ello, con independencia de la bondad técnica o las virtudes de una determinada modalidad retributiva, pues se trata de una materia que forma parte de la libertad de configuración legal que corresponde a la Cámara legislativa, y respecto a la que este Tribunal no puede ignorar el margen de aplicación en la interpretación de la legalidad parlamentaria (por todas SSTC 242/2006, de 24 de julio, FJ 4, y 141/2007, de 18 de junio, FJ 4)».

118 «Las retribuciones devengadas en fecha anterior a la entrada en vigor del Reglamento forman ya parte del patrimonio de los Diputados, pero con respecto a las devengadas después de ese fecha los Diputados sólo tenían, al tiempo del cambio normativo, una mera expectativa de derecho [...] siendo de aplicación nuestra doctrina según la cual la irretroactividad sólo es aplicable a los derechos consolidados, asumidos e integrados en el patrimonio del sujeto y no a los pendientes, futuros, condicionados o las meras expectativas [...] por no ser su régimen retributivo inalterable».

119 La austeridad debería adoptarse como principio inspirador de las actuaciones y acuerdos de los órganos de la institución parlamentaria. Así aparece en el punto sexto de la Declaración adoptada por la Conferencia de Presidentes de Parlamentos Autonómicos (COPREPA) EL 31 de enero de 2015: «Que en esta 
- que cualesquiera iniciativas que se adopten por la mayoría en solitario deberán tener como horizonte primordial el interés general, siempre con la debida protección de las minorías, sin pretender obtener una posición más ventajosa o favorable, sea en el plano electoral o en el ejercicio de las funciones parlamentarias.

\section{Código ético de los parlamentarios}

En esta enumeración de otras medidas para la recuperación de la confianza en el Parlamento, parece adecuada una referencia final a la posible implantación de un código ético de los parlamentarios ${ }^{120}$. El Informe GRECO 2013-2014 sobre España recomienda que cada Cámara elabore y apruebe un código de conducta con la participación de sus miembros y que sea de fácil acceso para los ciudadanos, que incluya asesoramiento sobre, por ejemplo, la prevención de conflictos de intereses, regalos y otras ventajas, actividades complementarias e intereses financieros, requisitos de publicidad; y que se complemente con medidas prácticas para su puestas en práctica, incluso a través de una fuente institucional de asesoramiento confidencial que proporcione a los parlamentarios orientación y asesoramiento sobre cuestiones éticas y posibles conflictos de intereses, así como con actividades formativas especializadas.

Parece que más que un código ético ${ }^{121}$, lo que habría que conseguir es disponer de una normativa adecuada y exigir su cumplimiento riguroso ${ }^{122}$, a la vez que

nueva etapa, los Parlamentos Autonómicos deben consolidar y mantener el principio de máximo rigor y austeridad en el gasto».

120 Como afirma Rodriguez Arana, J., Ética institucional (Mercado «versus función pública»), Dykinson-Escola Galega de Administración Pública, Madrid, 1996, toda ética es personal.

121 Para el análisis de un ejemplo comparado, puede verse DARANAS, M., «Normas de conducta de los diputados del Reino Unido de Gran Bretaña e Irlanda del Norte», Revista de las Cortes Generales n. ${ }^{\circ} 88,2013$, p. $310 \mathrm{y}$ ss.

122 En el mismo sentido, García Mexía, P. («La ética pública, perspectivas actuales», Revista de Estudios Políticos, n. ${ }^{\circ} 114,2001$, p. 153): bastaría con la simple interpretación «éticamente sensible» de los preceptos jurídicos existentes, muy singularmente de los constitucionales. Los códigos de conducta son mecanismos de control ético público positivo porque pretenden persuadir a sus destinatarios y se proponen incentivar la actuación ético pública mediante estímulos deontológicos y axiológicos (p. 154). Véase también Ruiz-Rico Ruiz, G.: «La lucha contra la corrupción desde el Estado constitucional de Derecho: la legislación sobre financiación de partidos políticos en España», Cuadernos Manuel Giménez Abad, n. ${ }^{\circ}$ 7, 2014, p. 225 y ss.: mediante la creación de unos códigos de conducta o comportamiento institucional se pretende «la confección de una deontología precisa de obligaciones que, situadas en el plano de la ética, conlleven igualmente efectos en la esfera jurídica y sancionatoria; el objetivo no es otro que forzar a quienes gobiernan, en general al estamento de lo político, a actuar conforme a un doble patrón de ejemplaridad moral y legalidad». En el ámbito del ejecutivo, véase como ejemplo la Orden 516/2005, de 3 de marzo, que publica el Acuerdo del Consejo de Ministros de 18 de febrero de 2005, por el que se aprueba el Código de Buen Gobierno de los miembros del Gobierno y de los altos cargos de la Administración General del Estado, y la Ley 3/2015, de 30 de marzo, reguladora del ejercicio del alto cargo de la Administración General del Estado (que deroga el citado Acuerdo, así como la Ley 5/2006, de 10 de abril, de regulación de los conflictos de intereses de los miembros del Gobierno y de los altos Cargos de la Administración General del Estado y su Reglamento aprobado por Real 
desarrollar en los políticos la conciencia de una ética pública. Pero a veces tales códigos persiguen más bien un objetivo pedagógico, a la vez que se presentan como instrumentos para la recuperación del prestigio de la clase política.

\section{CONCLUSIÓN}

Las realidades, proyectos y propuestas en materia de transparencia y participación ciudadana tienen como último objetivo la regeneración del Parlamento, en aras de la recuperación de la confianza de los ciudadanos. Es importante recordar que las modificaciones normativas que se introduzcan, para que surtan los efectos pretendidos, deben ir acompañadas de una voluntad política de renovación, no sólo en las funciones de la institución parlamentaria sino también en la transparencia y la ética de los actores políticos.

De la regeneración de la institución puede depender la recuperación de su papel central en el sistema político, así como la superación del déficit de representación que perciben los ciudadanos mediante el reforzamiento de la relación entre representantes y representados.

TITLE: Regeneration of Parliament, transparency and citizen participation

AвSTRACT: The prevailing mistrust in the political system and institutions bas also reached the parliamentary institution, accused of a lack of representation. The article arises, for the sake of a possible regeneration of Parliament, a diagnosis of the situation and the search for solutions, particularly in the renewal of parliamentary functions and the mechanisms of transparency and citizen participation in course of implementation in the Spanish Chambers, as instruments to try to regain the public trust, and ultimately the central role of Parliament in the institutional framework.

Resumen: La desconfianza en el sistema político y el descrédito de las instituciones imperante hoy día alcanza también al Parlamento, acusado de un déficit de representación. El art. se plantea, en aras de una posible regeneración de la institución, un diagnóstico de la situación y la buisqueda de soluciones, en particular en la renovación de las funciones parlamentarias y en los mecanismos de transparencia y participación ciudadana, en curso de implantación en las Cámaras españolas como instrumentos para tratar de recuperar la confianza pública y en último término su papel central en el entramado institucional.

KeY words: Parliament, Parliament crisis, democratic regeneration, parliamentary transparency, citizen participation.

Palabras Clave: Parlamento, crisis del Parlamento, regeneración democrática, transparencia parlamentaria, participación ciudadana.

FECHA DE RECEPCIÓN: 23.04.2015

FECHA DE ACEPTACIÓN: 29.07.2015

Decreto 432/2009). Véase también el art. 15 del Texto Refundido del Reglamento del Parlamento de Cataluña, que encomienda a la Comisión de Reglamento la elaboración y aprobación de un código de conducta de los parlamentarios. 